Research Article

\title{
Influence of In-Situ Stress on the Energy Transmission of Blasting Stress Wave in Jointed Rock Mass
}

\author{
Qian Dong $\mathbb{D},{ }^{1,2}$ XinPing Li $\mathbb{D},^{3}$ and TingTing Liu $\mathbb{C}^{3}$ \\ ${ }^{1}$ Hubei Key Laboratory of Blasting Engineering, Jianghan University, Wuhan, Hubei 430056, China \\ ${ }^{2}$ Hubei (Wuhan) Institute of Explosion Science and Blasting Technology, Jianghan University, Wuhan, Hubei 430056, China \\ ${ }^{3}$ Hubei Key Laboratory of Road-Bridge and Structure Engineering, Wuhan University of Technology, Wuhan, \\ Hubei 430070, China \\ Correspondence should be addressed to Qian Dong; dongqian@jhun.edu.cn
}

Received 1 June 2021; Accepted 15 September 2021; Published 12 October 2021

Academic Editor: Bangbiao Wu

Copyright (C) 2021 Qian Dong et al. This is an open access article distributed under the Creative Commons Attribution License, which permits unrestricted use, distribution, and reproduction in any medium, provided the original work is properly cited.

\begin{abstract}
The study of influence of in-situ stress on energy transmission of blasting stress wave in jointed rock mass is the basis for improving the utilization rate and optimizing the distribution of explosive energy in underground rock mass during blasting excavation. Thus, a model test was carried out to explore the energy transmission of blasting stress wave in jointed rock mass under different in-situ stresses, and the energy transmitting coefficients of the blasting stress wave were derived. Then, the influencing factors such as the scale and distribution of in-situ stresses and the angle and number of joints were discussed, respectively. The results showed that the energy transmission of blasting stress wave in jointed rock mass was affected by both the intact rock and joints, and the energy transmitting coefficients first increased and then decreased with the rise of static load and lateral static load coefficient, indicating that the lower in-situ stress can enhance the energy transmission of stress wave in rock mass to some extent. While the in-situ stress was relatively large, the stress wave energy dissipation in intact rock was dominant. The number and angle of joints also had a remarkable impact on the energy attenuation of the stress wave; when the stress wave was vertically incident on the joints, the energy transmitting coefficient was the largest. For underground engineering, the orientation of the dominant structural plane and the in-situ stress state of rock mass should be determined firstly, and the blasting parameters can be optimized to improve the utilization of explosive energy and achieve the designed blasting effect.
\end{abstract}

\section{Introduction}

In the natural or human activities such as earthquake, mining and blasting excavation in the underground rock mass, different magnitude of stress waves will be produced. Meanwhile, joints that widely exist in the natural rock mass significantly affect the stress wave propagation [1]. The propagation of stress wave in jointed rock mass is always accompanied by energy transmission, attenuation, and dissipation. Moreover, underground rock mass is inevitably located in a certain in-situ stress environment. Hence, the exploration of energy transmission of stress wave across the in-situ stressed jointed rock mass is of great significance to improve the utilization rate and optimize the distribution of the explosive energy in underground rock mass during blasting excavation.

Natural rock masses contain massive joints, which often control their mechanical behavior and have a great impact on the propagation of stress wave simultaneously [2-4]. To date, considerable theoretical researches on the stress wave propagation through joints of rock mass had been conducted, which can be roughly divided into two categories [5]. The first one is based on the theory of Discontinuous Deformation Method (DDM) [6], which supposed that the stresses on both sides of the joint are continuous during the passage of the stress wave, while the displacements are discontinuous. The DDM had been widely applied to investigate stress wave passing across linear and nonlinear 
deformational rock joints [7-9], one single joint and multiple parallel joints [10-12]. Other scholars combined the DDM with another analysis method, such as the method of characteristic line [13], scattering matrix method [14], and so on. Recently, the Layered Medium Model (LMM) was proposed for wave propagation across filled joints with the assumption that both displacements and stresses were continuous across the interface of two media $[15,16]$. The other category method is based on the Equivalent Medium Method (EMM), where effective elastic moduli were calculated and used to represent the jointed medium, such as virtual wave source method $[17,18]$. However, these theoretical methods rarely took into account the effect of initial stress.

On the other hand, experimental researches on the stress wave propagation in the rock mass were mainly through the Split Hopkinson Pressure Bar (SHPB) apparatus [19-21]. Meanwhile, to consider the effect of initial stress on stress wave propagation, some scholars had added the confining pressure and axial pressure loading device to the conventional SHPB apparatus, and the related studies had focused on the effect of in-situ stress on the dynamic mechanical properties of the rock mass $[22,23]$. Nevertheless, few works had been carried out on the propagation and attenuation of stress waves in jointed rock mass under initial stress by experimental means.

Underground rock masses are initially subjected to insitu stress before blasting excavation, and the presence of insitu stress affects mechanical properties of joints and intact rock and the stress wave propagation $[24,25]$. The existence of initial stress not only affects the propagation of stress wave in intact rock but also alters the stress state of the joints, thus changing the stress wave propagation in rock mass. Fan and Sun [26] used the nonlinear Barton-Bandis model to simulate the deformation characteristic of the joints, and utilized the DDM to study the seismic wave propagation through an in-situ stressed rock mass. Cheng et al. [27] investigated the effect of increasing static stress on attenuation mechanism and energy dissipation of stress wave in sandstone by an improved SHPB apparatus.

For some critical issues in blasting excavation of natural rock mass, such as low utilization rate of explosive energy and unclear distribution of explosive energy in rock mass, so that the rock mass cannot be fragmented effectively and adequately. To solve the above problems, the energy transmission of the blasting stress wave in the jointed rock mass should be clarified, and the blasting excavation parameters of the rock mass can be optimized. Thus, it is necessary to survey the energy transmission of the stress wave in jointed rock mass to fully understand stress wave propagation and attenuation mechanism. Some scholars studied the energy transmission and attenuation of stress wave in jointed rock mass by theoretical or experimental approaches [28-30]. However, researches on the effect of static stress on the stress wave energy transmission in jointed rock mass were comparatively scarce, especially through experimental methods.

Therefore, in the present study, a model test of stress wave propagation in jointed rock mass under different in- situ stresses (equal and unequal biaxial static loading) was carried out. Based on the stress and strain time-history curves measured at different positions in the model test samples and the stress wave propagation theory, the energy transmitting coefficient of stress wave was derived; consequently, the energy transmission of blasting stress wave in intact rock and jointed rock mass under different in-situ stresses was comparative analyzed. Furthermore, the influencing factors of the stress wave energy transmission, such as the scale and distribution of static loads, the angle and the quantity of joints were discussed, respectively.

\section{Model Test of Stress Wave Propagation}

2.1. Static Loading Apparatus. The multifunctional testing machine for rock and soil was adopted to provide steady and uniformly distributed static boundary loads in the model test, as shown in Figure 1. Meanwhile, the length, height, and thickness of the model test sample are $1600 \mathrm{~mm}, 1300 \mathrm{~mm}$, and $400 \mathrm{~mm}$, respectively, and the schematic diagram of the static loads applied to the sample during the test is shown in Figure 2, in which the $P_{\mathrm{V}}$ and $P_{\mathrm{H}}$ represent the vertical and horizontal boundary static loads, respectively.

2.2. Mechanical Properties of the Intact Rock and Joint Simulation Material. It is well known that the natural rock masses are composed of intact rock and discontinuities such as joints and fissures, and these discontinuities are considered as the weak planes in terms of mechanical properties compared with intact rock, and the mechanical behavior of the rock masses are often controlled by the discontinuities. Therefore, the mechanical strength of the intact rock simulation material should be greater than that of the joint simulation material in the model test. To accurately simulate geological structure characteristics of underground rock masses, cement mortars and mica plates were adopted as simulation materials of intact rock and joints, respectively, to investigate the effect of in-situ stress on the stress wave energy transmission in jointed rock mass. The detailed determination process of similarity coefficients and simulation materials in model test can refer to the literature $[31,32]$, and is only briefly described in this paper, as follows:

(1) The stress similarity coefficient $C_{\sigma}$ between the intact rock simulation material and the prototype of deepburied underground engineering surrounding the rock was 20, and the physical and mechanical parameters of the prototype are presented in Table 1.

(2) In order to avoid the influence of nonuniform aggregate in concrete materials on the propagation of blasting stress wave, the low strength cement mortar without aggregate was selected as the intact rock simulation material.

(3) In the model test, the mixture ratio of cement mortar in accordance with the similarity theory was determined through the orthogonal tests, which were cement: sand: water: plasticizer $=1: 4: 1.2: 0.0267$. Through a series of tests, the mechanical parameters 


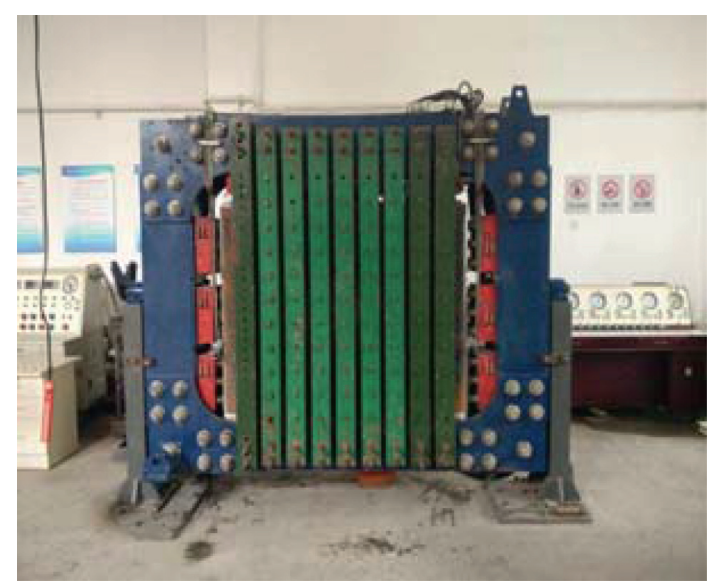

FIGURE 1: Multifunctional testing machine for rock and soil.

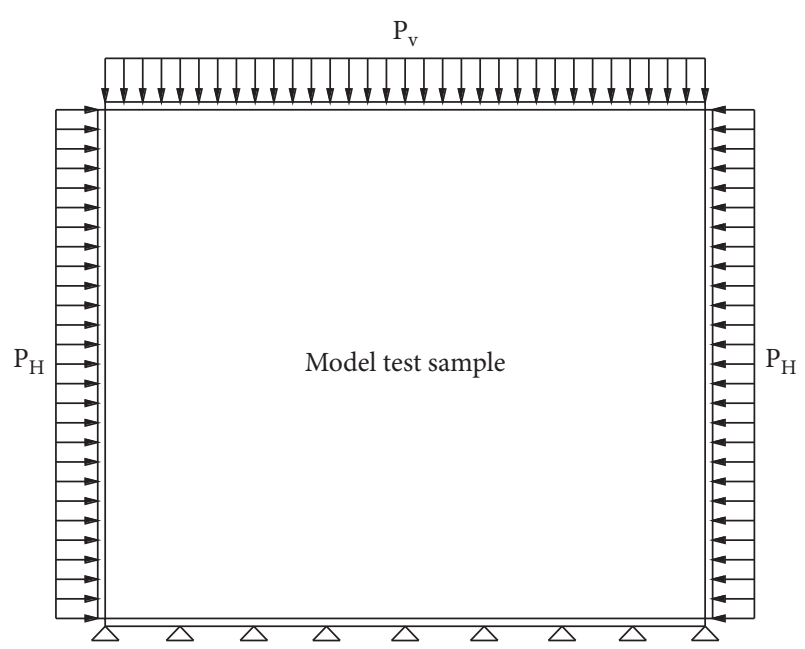

Figure 2: The schematic diagram of the static loads applied to the test sample.

TABle 1: Physical and mechanical parameters of similar materials and prototype of intact rock.

\begin{tabular}{lcc}
\hline Parameters & Prototype & Similar material \\
\hline Uniaxial compressive & 120 & 5.864 \\
strength $R c(\mathrm{MPa})$ & 12 & 0.613 \\
Tensile strength $\sigma t(\mathrm{MPa})$ & 50 & 5.226 \\
Elastic modulus $E(\mathrm{GPa})$ & 30 & 23.2 \\
Internal friction angle $\varphi\left({ }^{\circ}\right)$ & 30 & 1.49 \\
Cohesion $c(\mathrm{MPa})$ & 0.223 & 0.203 \\
Poisson ratio $\mu$ & 2600 & 1980 \\
Density $\rho\left(\mathrm{kg} / \mathrm{m}^{3}\right)$ & &
\end{tabular}

of the cement mortar material of the chosen mixture ratio are shown in Table 1.

(4) The joints in the in-situ stressed rock mass are in a closed state of compression, so the joints in the model test samples were made into closed joints. While the wave length of the blasting stress wave is greater than the joint thickness, the influence of the joint thickness on the stress wave propagation can be ignored. Therefore, in the model test samples, the mica plates with a thickness of $1 \mathrm{~mm}$ were used to be the joint simulation material, as shown in Figure 3(a).

(5) The typical relationship curve between the normal stress and the compressive deformation of mica plates was obtained through the normal compression test, as shown in Figure 3(b). It can be observed that the normal stress and deformation of joint simulation material shows a nonlinear relationship, which is consistent with the mechanical properties of joints in the in-situ stressed rock mass [8].

2.3. Design and Fabrication of Model Test Samples. The energy transmission of the blasting stress wave in jointed rock mass is related to the angle, quantity, and mechanical properties of joints, and also affected by the scale and distribution of in-situ stress. Hence, three different model samples, named $T 1, T 2$, and $T 3$, respectively, were designed to study the effect of in-situ stress on the energy transmission of blast stress wave in intact rock and rock mass with different angles and numbers of joints, as shown in Figure 4.

Based on the structural characteristics of the cylindrical charge of the model samples, it can be probably considered that the original blasting stress wave generated from the blast source in the model samples is the same in all directions. Consequently, to take full advantage of the model samples and improve the test efficiency, four measuring lines were arranged in each model test sample, respectively, which were along the line direction of the blast source and the midpoint of the four sides of the test samples. For example, the designed $\mathrm{T} 1$ test sample was used to study the energy transmission of blasting stress wave vertical incident jointed rock mass under different in-situ stresses. As a contrast, the energy transmission of the stress wave in intact rock without joints was also considered. According to the number of joints in the four measuring lines, the corresponding research objects are intact rock, single-joint rock mass, doublejoints rock mass, and triple-joints rock mass. Besides, the T2 and T3 test samples were designed to study the energy transmission of blasting stress wave in intact rock and rock mass containing joints with different numbers and angles. Refer to the $T 1$ test sample, the corresponding research objects of the $T 2$ and $T 3$ test samples are intact rock and single-joint and double-joints rock masses of $30^{\circ}, 60^{\circ}$ and $90^{\circ}$, respectively.

In addition, all the measuring lines contained in the three model test samples were arranged with the strain sensors and the PVDF (Polyvinylidene fluoride) stress sensors, which were located at $150 \mathrm{~mm}$ and $350 \mathrm{~mm}$ from the blasting source along the radial propagation direction of the stress wave in each measuring line, as shown in Figure 4. The strain sensors and the PVDF stress sensors were self-made, and the fabrication process of a single strain sensor was as follows: The BE120-5AA resistance strain gauge was firstly bonded to the polyethylene sheet with the size of $8 \mathrm{~mm}$ (length) $\times$ $8 \mathrm{~mm}$ (width) and then connected to the shielding wires. At the same time, the surface of the strain gauge was coated 


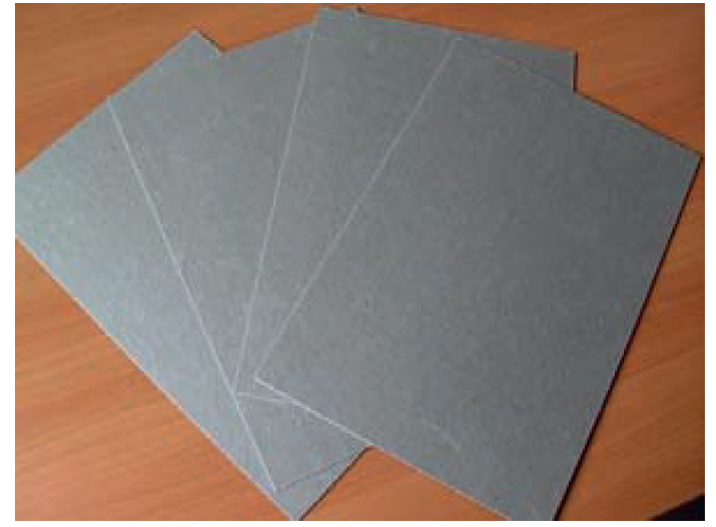

(a)

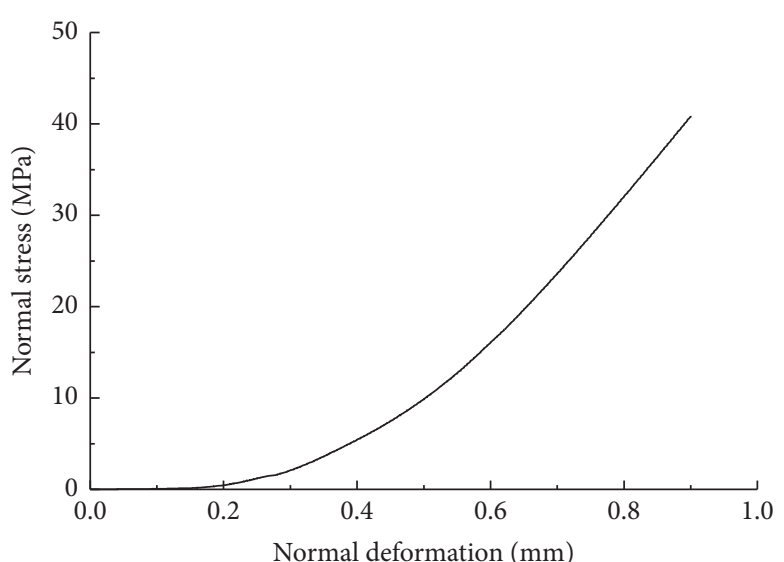

(b)

Figure 3: Joint simulation material and its mechanical properties. (a) The mica plates. (b) Normal stress and deformation curve.

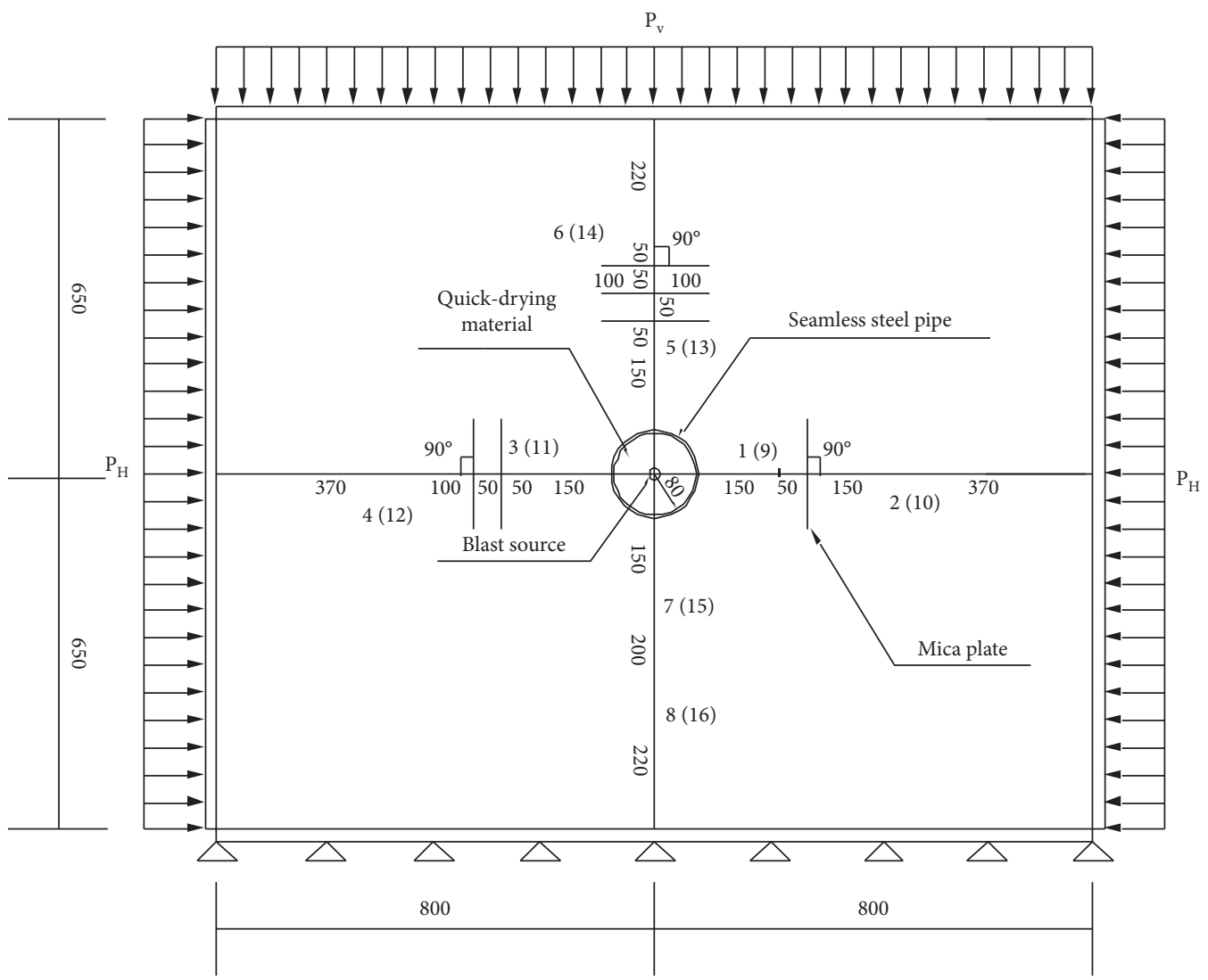

(a)

Figure 4: Continued. 


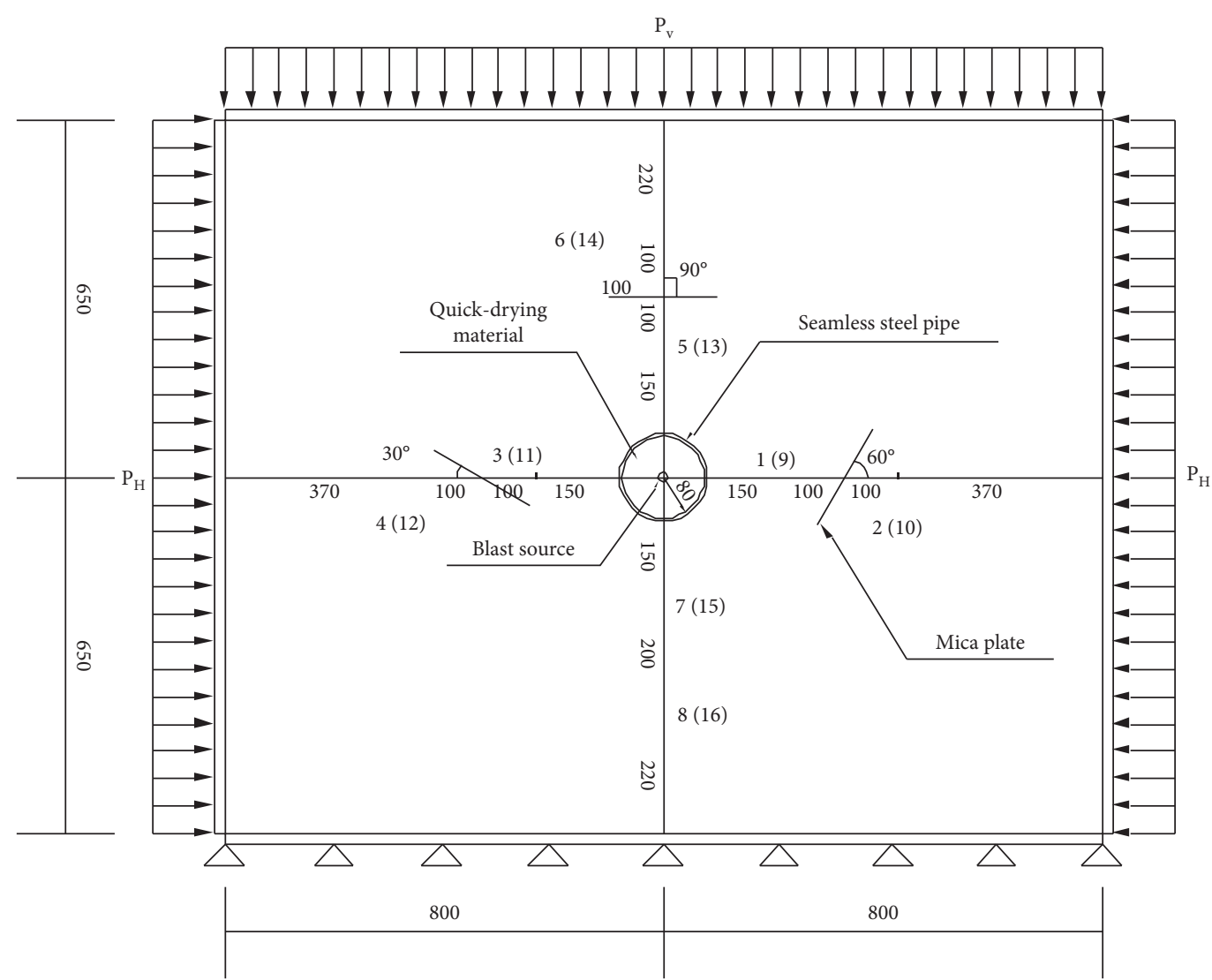

(b)

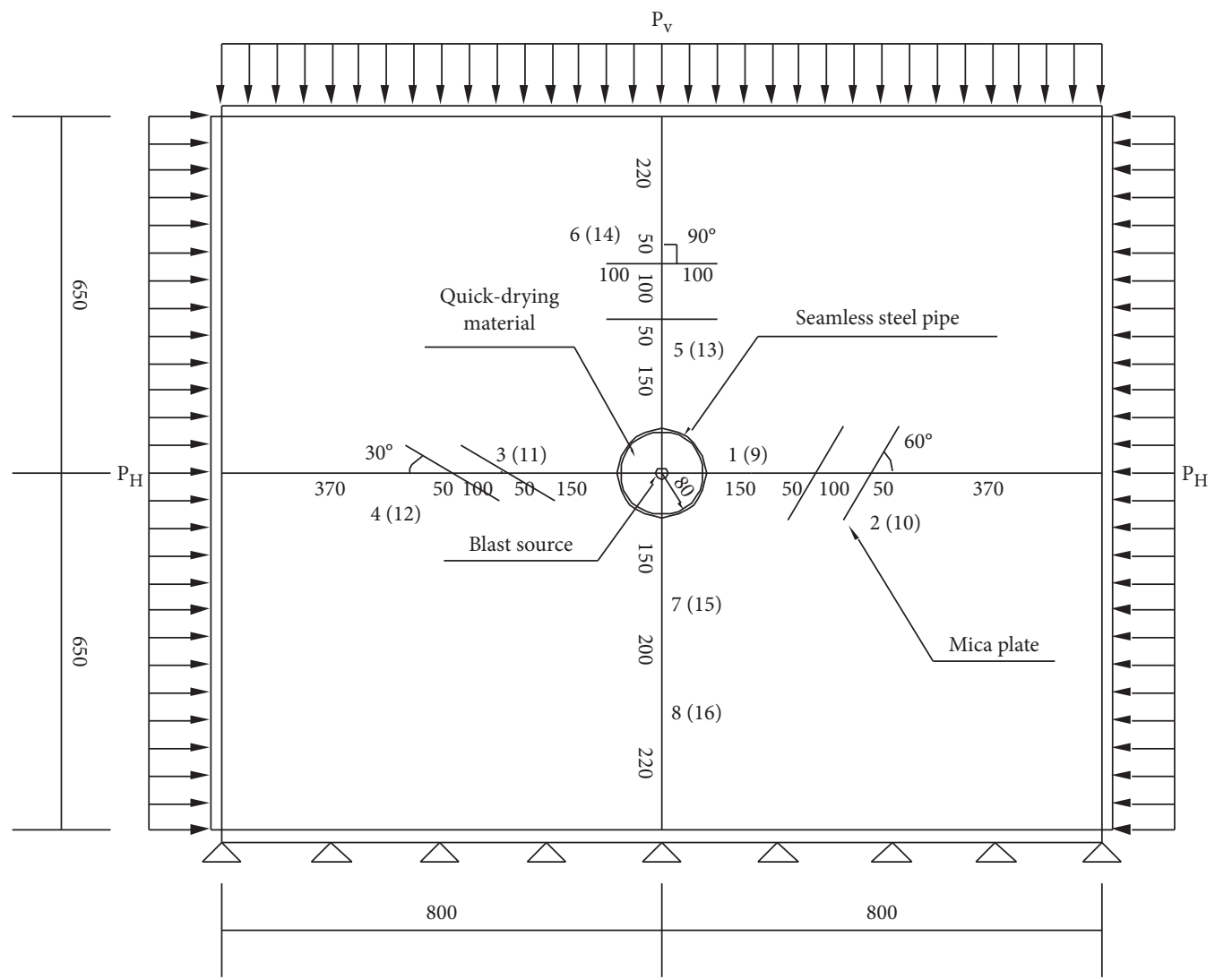

(c)

FIGURE 4: Layout of measuring points and joints of model test samples (unit: mm). (a) T1 sample. (b) T2 sample. (c) T3 sample. 
with epoxy resin and evenly adhered with the sand. The purpose of this treatment is to avoid the influence of water on the strain gauge during the casting of the model samples, and to increase the match between the strain sensor and the model sample materials as shown in Figure 5(a). On the other hand, the PVDF stress sensors were based on the piezoelectric effect principle of the polyvinylidene fluoride to measure external pressure changes. Meanwhile, to protect the sensitive components and ensure the stress uniformity of the sensor structure, a circular protective substrate made of stainless steel was designed. The fabricated PVDF stress sensor had a diameter of $40 \mathrm{~mm}$, a thickness of $5 \mathrm{~mm}$, and a maximum range of $50 \mathrm{MPa}$, which was also connected by shielded cables as shown in Figure 5(b).

Due to the different piezoelectric effect of polyvinylidene fluoride sensitive components, it is necessary to calibrate the sensitivity coefficient of each PVDF stress sensor, and the instruments used for the calibration were an oil pressure tank, an oil pump, a charge amplifier and a voltmeter. The calibration process was as follows: the PVDF stress sensors were firstly connected to the charge amplifier and placed in the oil pressure tank, while different oil pressures were applied by using the oil pump, and several sets of pressure values and the corresponding voltage values were recorded to obtain the sensitivity coefficients, which ranged from 1761 to $2290 \mathrm{pC} / \mathrm{MPa}$ for the PVDF stress sensors used in the model test. Moreover, the strain sensors fabricated were based on conventional resistive strain gauges as sensitive elements, and the factory-calibrated sensitivity factor of 2.12 for the resistive strain gauges was adopted during the dynamic testing.

In each test sample, the number of the strain and stress measuring points varied from 1 to 8 and 9 to 16 illustrated in Figure 4, respectively. According to the cylindrical charge structure of test samples, the stress and strain test sections were set at different thickness of samples. Meanwhile, the stress and strain measurement points at the same distance from the blasting source are ensured to be projected in the direction of the thickness of the test samples. Each model test sample was divided into three layers for pouring, and the thickness of the first layer was $150 \mathrm{~mm}$ and cured for 1 day. When the layer surface reached the certain strength, the selfmade PVDF pressure sensors were embedded. Then, the second layer with the thickness of $100 \mathrm{~mm}$ was poured, and resistive strain sensors were embedded on its surface after 1 day's maintenance. Finally, the third layer with a thickness of $150 \mathrm{~mm}$ was poured. After 28 days of maintenance, the fabricated model test samples can be applied to the explosive loads. The blasting stress wave imposed in the model test samples was generated by four detonating cords with a total length of $1.6 \mathrm{~m}$, and the TNT (Trinitrotoluene) equivalence is about $17.6 \mathrm{~g}$. The detonating cords were fixed in the seamless steel pipe in the center of the test samples through the wooden centering stent, as shown in Figure 6.

2.4. Model Test Procedure. In order to improve the efficiency of the model test, the method of repeatedly applying blasting load on a single model test sample was adopted, and different initial static load conditions were set simultaneously. The detailed test steps are as follows:

Firstly, the fabricated and cured model test samples were hoisted to the multifunctional testing machine for rock and soil (seen in Figure 1), and the four detonating cords were fixed in the center of the seamless steel pipe of the test samples through the wooden centering stent (seen in Figure 6). Quick-drying materials were selected as the filling material and loading core of seamless steel pipes in the test samples, subsequently poured into the pipes and cured for 1 day to reach the strength similar to the model test material.

Secondly, the static loads of different scales and distributions were applied to the model test samples by static loading apparatus, and to ensure the strain uniformity of the model test samples, the static loads were applied to the preset value in two steps, and stabilized for 15 and 30 minutes, respectively.

Thirdly, after the static loads were applied, the dynamic data acquisition instrument DH 5960 was set to the state to be triggered, and then the detonating cords were detonated by the electric detonator, and the dynamic stress and strain data of different positions in the model test samples were collected synchronously with the sampling frequency of $2 \mathrm{MHz}$.

Finally, after data acquisition, the quick-drying materials in the seamless steel pipes in each model test sample can be broken and cleaned out by an electric drill. Then, the new detonating cords and quick-drying materials were placed in the steel pipes, and the next blasting test can be carried out.

In the model test, according to the distribution of the insitu stresses of the underground engineering surrounding the rock mass and the stress similarity coefficient, 20 blasting tests under static loading conditions of different scales and distributions were carried out on the three model test samples, as shown in Table 2. The symbols $P_{\mathrm{V}}$ and $P_{\mathrm{H}}$ represented the vertical and horizontal boundary static loads exerted to the samples as shown in Figure 4, and the corresponding lateral static load coefficient was the ratio of $P_{\mathrm{H}}$ to $P_{\mathrm{V}}$. The static loads applied to the $T 1$ test sample were from NO.1 to NO.4, designing for the equal biaxial static loading. While for the $T 2$ and $T 3$ samples, the static loads were from NO.1 to NO.8 in Table 2, including the equal and unequal biaxial static loading.

\section{Energy Transmitting Coefficient of Blasting Stress Wave}

According to the theory of stress wave propagation, in each test sample, when the blasting stress wave produced by the detonating cords propagates to the stress and strain measurement point before the joint, a small area $\mathrm{d} A$ on the stress wave front around the measuring point was selected as the research object. Assuming in a small time $\mathrm{d} t$, stress wave radial propagation distance $\mathrm{d} l=c \mathrm{~d} t, c$ is the propagation velocity of the stress wave, as shown in Figure 7.

The energy $E_{I}$ of the incident stress wave in a small volume $\mathrm{d} V$ near the measuring point before the joint is: 


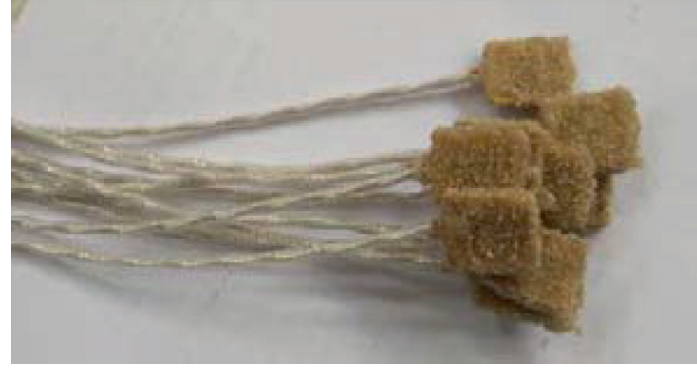

(a)

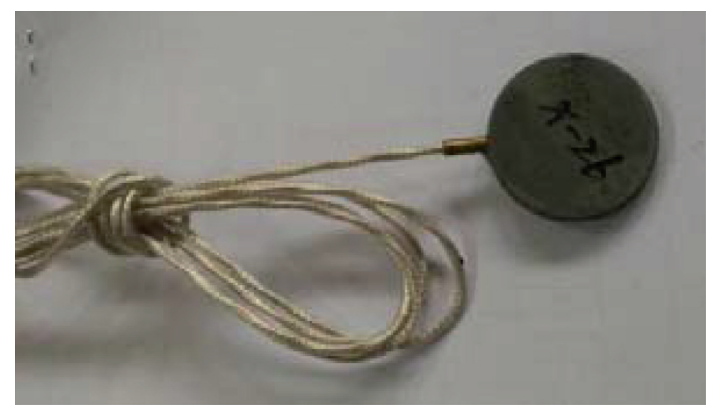

(b)

FIGURE 5: Stress and strain sensors in the model test samples. (a) Strain sensors. (b) A PVDF stress sensor.
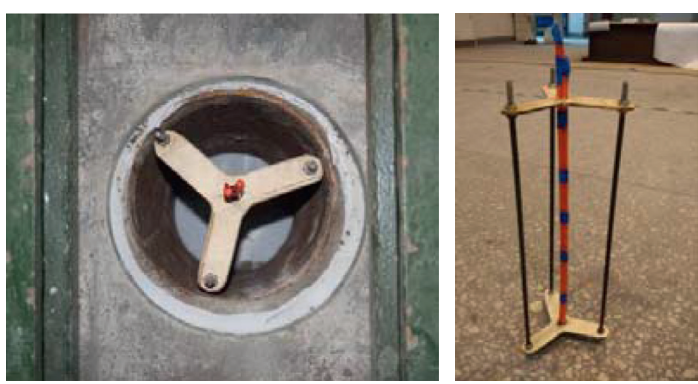

FIGURE 6: Schematic diagram of charge structure.

TABLE 2: Boundary static loads of model test samples.

\begin{tabular}{lcccc}
\hline & \multicolumn{2}{c}{$\begin{array}{c}\text { Static loads } \\
\text { No. }\end{array}$} & $\mathrm{MPa})$ & \multicolumn{2}{c}{ In-situ stresses $(\mathrm{MPa})$} \\
& $P_{\mathrm{V}}$ & $P_{\mathrm{H}}$ & Vertical & Horizontal \\
\hline 1 & 0 & 0 & 0 & 0 \\
2 & 0.75 & 0.75 & 15 & 15 \\
3 & 1.5 & 1.5 & 30 & 30 \\
4 & 3 & 3 & 60 & 60 \\
5 & 0.75 & 1.5 & 15 & 30 \\
6 & 1.5 & 0.75 & 30 & 15 \\
7 & 1.5 & 3 & 30 & 60 \\
8 & 3 & 1.5 & 60 & 30 \\
\hline
\end{tabular}

$$
\begin{aligned}
E_{I} & =\iiint_{V} \sigma_{I}(t) \varepsilon_{I}(t) \mathrm{d} V=\int_{0}^{l_{n}} \sigma_{I}(t) \varepsilon_{I}(t) \mathrm{d} A \mathrm{~d} l \\
& =\mathrm{d} A \int_{0}^{t_{n}} \sigma_{I}(t) \varepsilon_{I}(t) c \mathrm{~d} t,
\end{aligned}
$$

where $t_{n}$ and $l_{n}$ denote the propagation time and distance of the incident stress wave, respectively, and $\sigma_{I}(t)$ and $\varepsilon_{I}(t)$ are the stress and strain time-history curves of the measuring point before the joints. The energy intensity $I_{I}$ of the incident stress wave near the measuring point is

$$
I_{I}=\int_{0}^{t_{n}} \sigma_{I}(t) \varepsilon_{I}(t) c \mathrm{~d} t
$$

In the same way, the energy intensity $I_{T}$ of the transmitted stress wave is

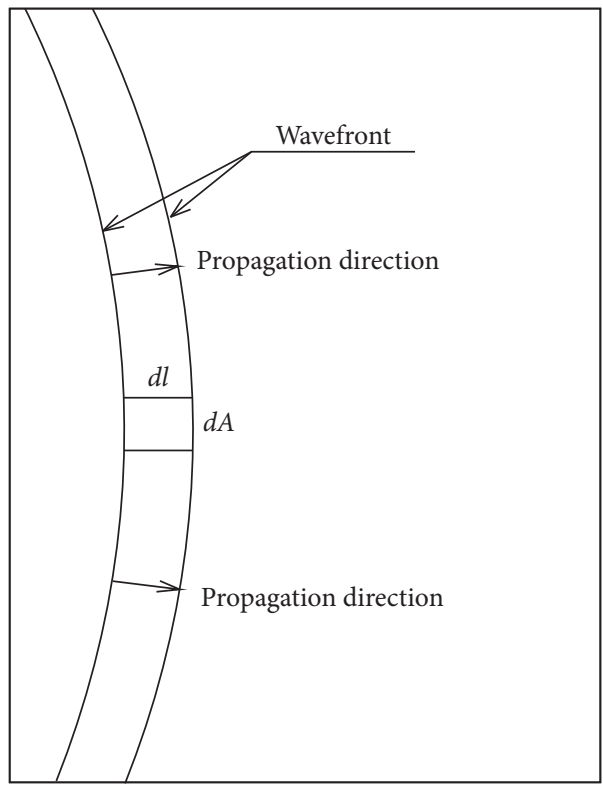

FIGURE 7: Sketch of blasting stress wave propagation near the measuring point.

$$
I_{T}=\int_{0}^{t_{m}} \sigma_{T}(t) \varepsilon_{T}(t) c \mathrm{~d} t
$$

where, $t_{m}$ denotes the propagation time of the transmitted stress wave, and $\sigma_{T}(t)$ and $\varepsilon_{T}(t)$ are the stress and strain time-history curves of the measuring point after the joints. 
To eliminate the effect of variation of the incident stress wave amplitude, the energy intensity ratio of the transmitted and the incident stress wave is defined as the energy transmitting coefficient $\eta$ of the stress wave passing through the jointed rock mass, as given below:

$$
\eta=\frac{\int_{0}^{t_{m}} \sigma_{T}(t) \varepsilon_{T}(t) \mathrm{d} t}{\int_{0}^{t_{n}} \sigma_{I}(t) \varepsilon_{I}(t) \mathrm{d} t} .
$$

\section{Energy Transmission of Blasting Stress Wave in the In-Situ Stressed Intact Rock}

As a comparison, the energy transmission of the blasting stress wave in intact rock under different in-situ stresses was analyzed first.

4.1. Effect of the Equal Biaxial Static Loads. Based on the stress and strain time-history curves obtained from the intact rock section in the three model test samples, the energy transmission of the blasting stress wave in the intact rock was investigated. To compare with the follow-up studies in the jointed rock mass, only the head waves of the stress and strain time-history curves were adopted for analysis. The energy intensity ratio of the head wave measured by strain measuring point 7 (stress measuring point 15) and strain measuring point 8 (stress measuring point 16) was defined as the energy transmitting coefficient of blasting stress wave in the intact rock. The strain and stress timehistory curves of intact rock in three test samples were obtained under different equal biaxial static loads, and the typical stress and strain time-history curves are shown in Figure 8.

Figure 8 showed a part of the strain and stress timehistory curves of the incident and transmitted waves in the intact rock section of the $T 1$ sample when the static load was $0 \mathrm{MPa}$, the curves all started at the same time, and lasted for $2 \mathrm{~ms}$. It can be seen from Figure 8 that the time when the blasting stress wave propagated to the strain measuring point 7 and stress measuring point 15, and the point 8 and 16 was almost consistent, meanwhile the head wave durations of the corresponding measuring points were almost the same. Hence, based on the head wave of the time-history curves recorded at the strain measuring point 7 and the stress measuring point 15 , the energy intensity of the incident stress wave can be obtained by the equation (4). Similarly, the energy intensity of transmitted stress wave can be obtained through the head wave of the curves recorded at the strain measuring point 8 and the stress measuring point 16.

After removing the outliers, the average values of the incident and transmitted stress wave energy intensity of the intact rock in three test samples under different equal biaxial static loads were sorted out. When the equal biaxial static loads were $0,0.75,1.5$, and $3 \mathrm{MPa}$, the incident wave energy intensities were $23.91,18.47,14.15$, and $7.76 \mathrm{~J} / \mathrm{m}^{2}$, respectively, and the energy intensities of the transmitted wave were $9.08,7.94,6.51$, and $2.56 \mathrm{~J} / \mathrm{m}^{2}$, respectively. The energy intensities of incident and transmitted stress wave in intact rock under different equal biaxial static loads are shown in Figure 9.

It can be can be observed in Figure 9 that the energy intensities of the incident and transmitted stress waves in the intact rock decrease with the increasing of the equal biaxial static load. The reason for the above phenomenon is that the larger the static stress, the stronger the interaction forces between particles of intact rock, so the vibration of intact rock induced by dynamic disturbance was more inhibited. Thus, the greater the static load, the smaller the dynamic response of the intact rock caused by the blasting stress wave, and the smaller the energy of the stress wave in the intact rock simultaneously. Meanwhile, the energy transmitting coefficients of the blasting stress wave in intact rock under different equal biaxial static loads are as shown in Figure 10.

When the static loads were $0,0.75,1.5$, and $3 \mathrm{MPa}$, the blasting stress wave energy transmitting coefficients were $0.38,0.43,0.46$, and 0.33 , respectively. It is reported that the energy transmitting coefficient of stress wave increases first and then decreases with the increase of static loads. In the model test, there were no obvious cracks and damage on the surface of the samples after explosive loading, so it is unnecessary to consider the stress wave energy dissipation caused by the fragment of the samples. Therefore, the energy dissipation of the blasting stress wave in the intact rock can be divided into two parts. The first part was the energy dissipation due to the geometrical dispersion of the stress wave front. Meanwhile, there were numerous micro-cracks inside the intact rocks, and when the stress wave propagates in them, it will drive the micro-cracks to slide overcoming the frictional forces, and another part of the stress wave energy was dissipated.

When the equal biaxial static load was less than $1.5 \mathrm{MPa}$ (i.e., 25.6\% of the uniaxial compressive strength $R_{\mathrm{c}}$ ), with the increase of static load, the micro-cracks in the intact rock were closed, the dynamic stress required for the sliding of the micro-cracks was increased simultaneously, and the quantity of micro-cracks that can slip under the stress wave was also reduced, so the energy dissipation of the stress wave decreased. When the static load reached a certain extent, and continued growing, the closed micro-cracks were expanded and new micro-cracks were initiated. Finally, the quantity of micro-cracks that can slip increased, so the energy dissipation of the stress wave was raised accordingly. It can be speculated that there was a critical static load $R_{\mathrm{cr}}(25.6 \%$ $R_{\mathrm{c}}<R_{\mathrm{cr}}<51.2 \% R_{\mathrm{c}}$ ); when the static load was greater than $R_{\mathrm{cr}}$, the number of micro-cracks in the intact rock grew, resulting in the fall of stress wave energy transmitting coefficients.

4.2. Effect of the Lateral Static Load Coefficient. When subjected to biaxial unequal static loading, the intact rock is in a state of differential stress loading, and the evolution of micro-cracks in the intact rock is closely related to the differential stress [33]. The influence of the lateral static load 


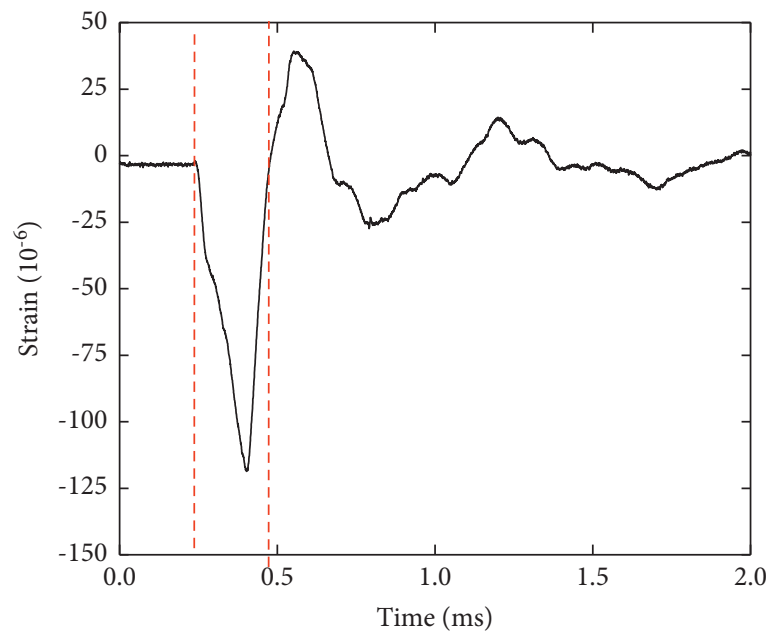

(a)

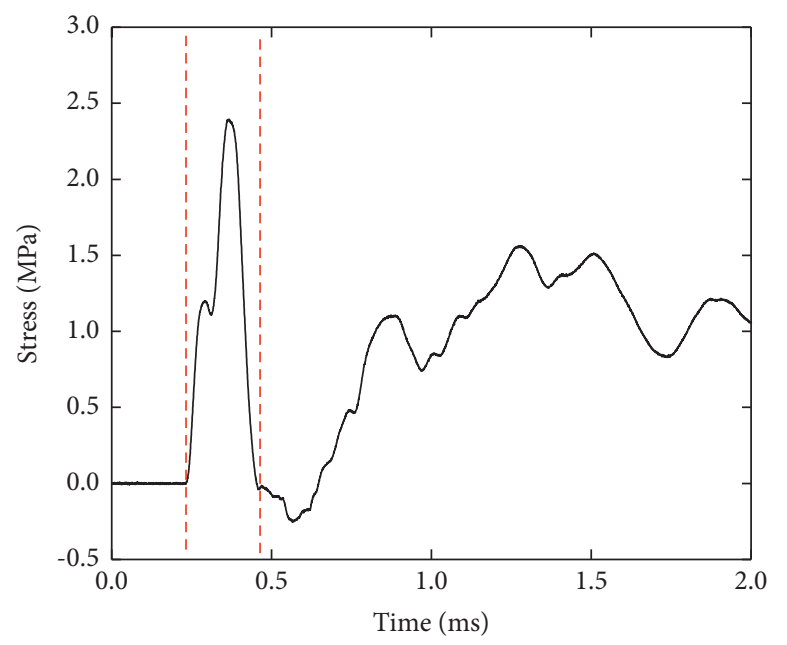

(c)

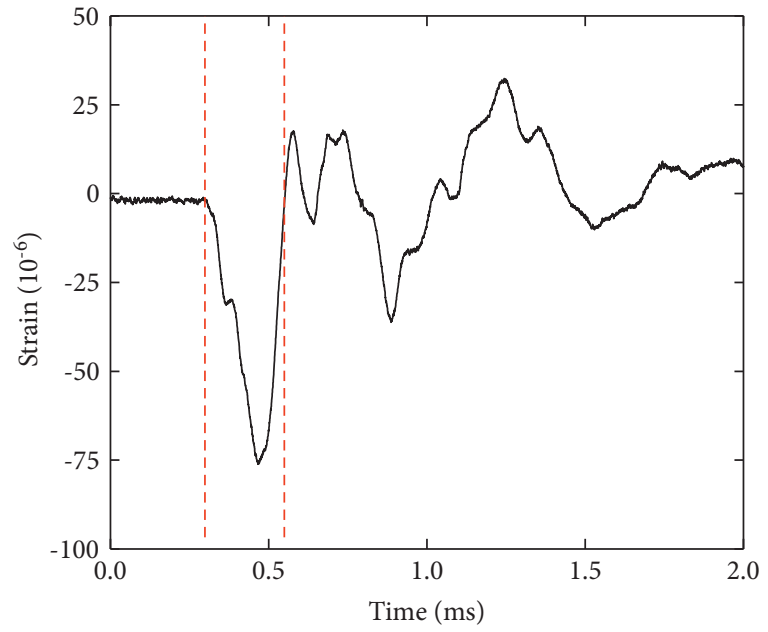

(b)

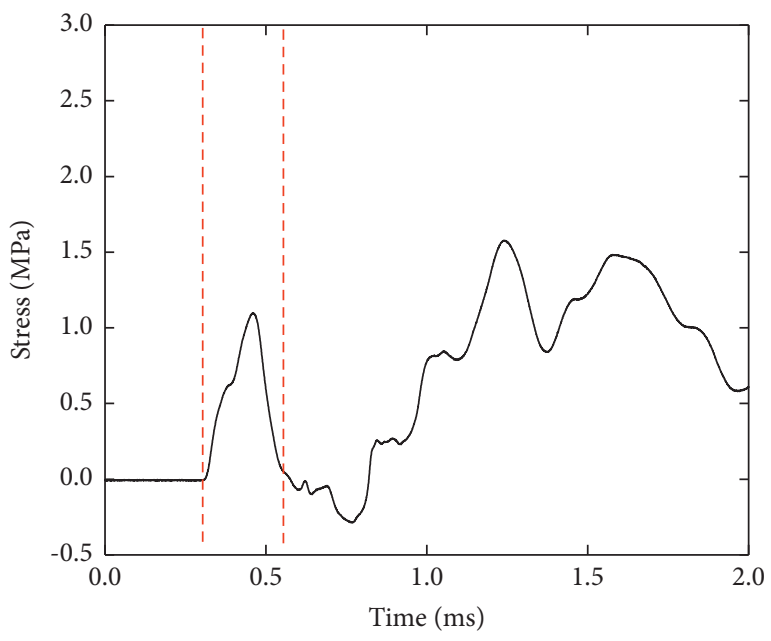

(d)

Figure 8: Typical incident and transmitted stress wave strain and stress time-history curves in intact rock. (a) Strain measuring point. (b) Strain measuring point 8. (c) Stress measuring point 15. (d) Stress measuring point 16.

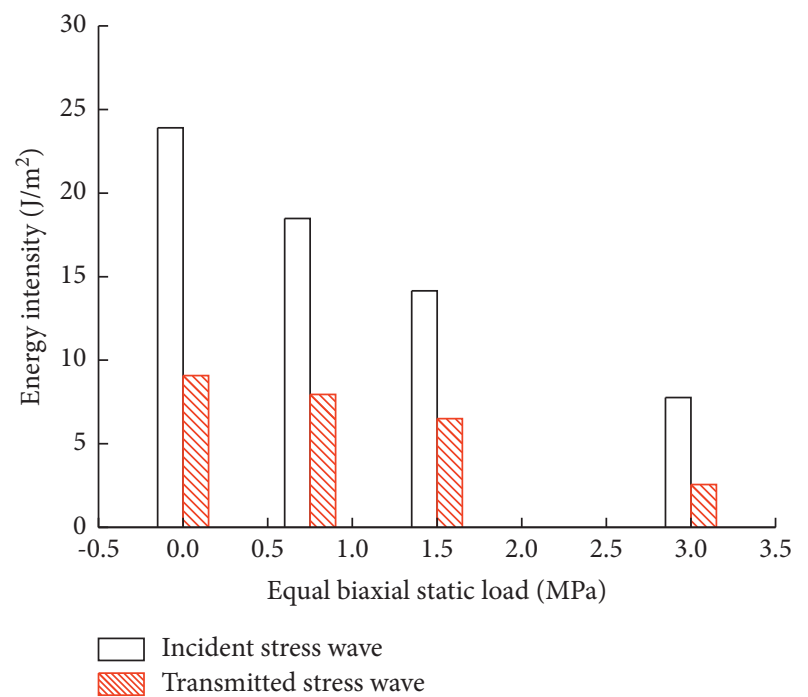

FIGURE 9: Energy intensities of incident and transmitted stress wave in intact rock under different equal biaxial static loads. 


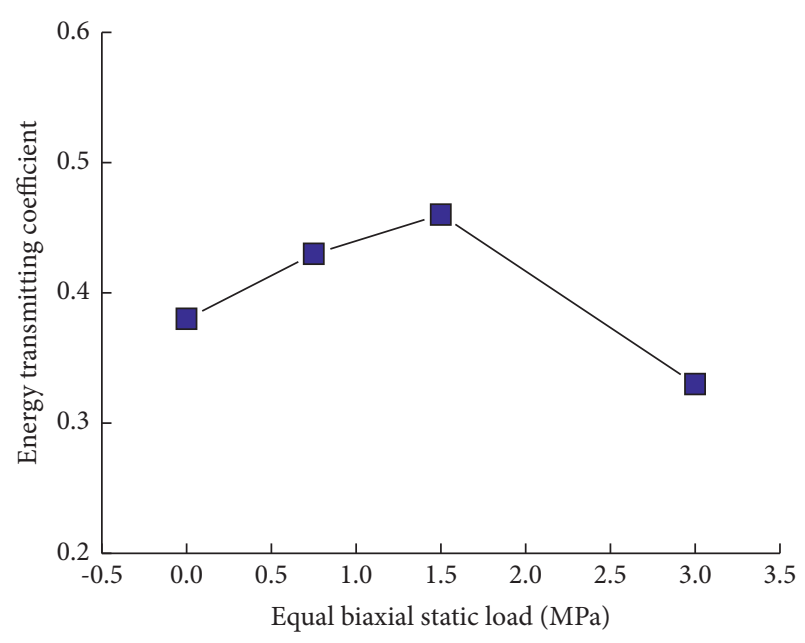

FIGURE 10: Energy transmitting coefficients of blasting tress wave in intact rock under different equal biaxial static loads.

coefficient on the stress wave energy transmission of the intact rock was studied under the static loading conditions of vertical loads of $1.5 \mathrm{MPa}$ and lateral coefficients of $0.5,1$, and 2 , respectively. The energy intensities of incident and transmitted stress waves under different lateral static load coefficients are shown in Figure 11.

It can be seen from Figure 11 that the energy intensity of the incident and transmitted stress waves decreased as the lateral static coefficient increased. The reason is that when the vertical static load was constant, the greater the lateral static load, the stronger the constraint on the vibration of the particles in the intact rock, so the energy of the blasting stress wave was smaller. According to the data in Figure 11, the energy transmitting coefficients of stress wave were $0.429,0.460$, and 0.371 , respectively, when the lateral static load coefficients were $0.5,1$, and 2 . The energy transmitting coefficient of the stress wave in the intact rock increased first and then decreased with the increase of the lateral static load coefficient. When the lateral static load coefficients were $0.5,1$, and 2 , the differential stresses for intact rock were $0.75,0$, and $1.5 \mathrm{MPa}$, respectively. The energy transmitting coefficients of stress wave under different differential stresses are shown in Figure 12.

Figure 12 shows that when the intact rock was subjected to biaxial unequal static loading, the energy transmitting coefficient of the stress wave decreased with the increase of differential stress. The reason is that the quantity of micro-cracks in the intact rock increased with the differential stress, and the quantity of micro-cracks that can slide under stress wave grew simultaneously, so the energy dissipation of the stress wave increased, and finally the energy transmitting coefficient of the stress wave continued to decline.

In summary, the test results implied that the change of static loading state will affect the development and evolution of micro-cracks in the intact rock, thus changing the energy transmission of the blasting stress wave.

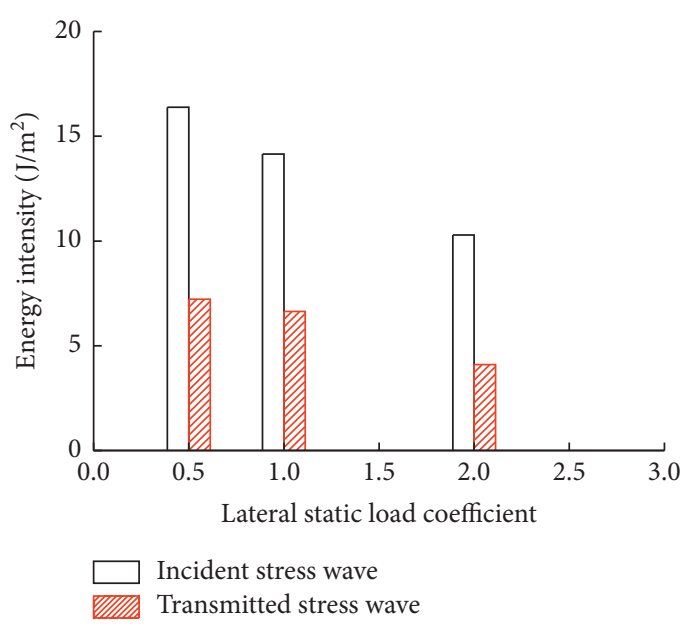

Figure 11: Energy intensities of incident and transmitted stress waves in intact rock under different lateral static load coefficients.

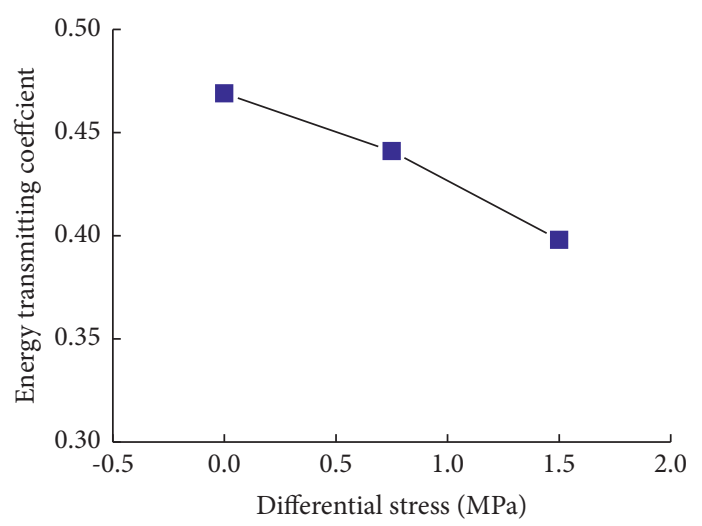

FIGURE 12: Energy transmitting coefficients of stress wave in the intact rock under different differential stresses.

\section{Energy Transmission of Blasting Stress Wave Normal Incident In-Situ Stressed Rock Mass}

5.1. Effect of the Equal Biaxial Static Loads. Based on the test results of T1 sample, the energy transmission of blasting stress wave normal incident jointed rock mass under different in-situ stresses can be obtained. The energy intensities of the blasting stress wave normal incident rock mass containing various numbers of joints under different equal biaxial static loads are shown in Table 3, and the abbreviations ISW and TSW represented incident and transmitted stress wave, respectively.

Table 3 manifested that the incident wave energy intensities of rock mass containing different numbers of joints were relatively close in the $T 1$ sample, indicating that the propagation of the blasting stress waves produced by the detonating fuses in all directions were uniform under equal biaxial static loads. Compared with the transmitted wave energy intensities in the intact rock under the same equal biaxial static loads, it can be found that the transmitted wave energy intensities of jointed rock mass and intact rock were 
TABLE 3: Energy intensities of incident and transmitted stress wave under different equal biaxial static loads.

\begin{tabular}{|c|c|c|c|c|c|c|}
\hline \multirow{2}{*}{ Static loads (MPa) } & \multicolumn{2}{|c|}{ Single-joint rock mass } & \multicolumn{2}{|c|}{ Double-joints rock mass } & \multicolumn{2}{|c|}{ Triple-joints rock mass } \\
\hline & $\operatorname{ISW}\left(\mathrm{J} / \mathrm{m}^{2}\right)$ & $\operatorname{TSW}\left(\mathrm{J} / \mathrm{m}^{2}\right)$ & $\operatorname{ISW}\left(\mathrm{J} / \mathrm{m}^{2}\right)$ & $\operatorname{TSW}\left(\mathrm{J} / \mathrm{m}^{2}\right)$ & ISW $\left(\mathrm{J} / \mathrm{m}^{2}\right)$ & $\operatorname{TSW}\left(\mathrm{J} / \mathrm{m}^{2}\right)$ \\
\hline 0 & 22.54 & 4.33 & 24.76 & 3.32 & 21.23 & 2.02 \\
\hline 0.75 & 16.32 & 5.63 & 19.41 & 5.30 & 17.59 & 3.99 \\
\hline 1.5 & 14.85 & 6.29 & 13.19 & 4.89 & 15.78 & 5.18 \\
\hline 3 & 8.43 & 2.68 & 6.65 & 2.01 & 6.33 & 1.80 \\
\hline
\end{tabular}

quite different, illustrating that the existence of joints will dissipate the energy of stress wave. Meanwhile, the greater the quantity of joints, the smaller the energy intensities of the transmitted wave. To conclude, with the increase of static loads, the energy intensities of incident and transmitted wave in rock mass containing different numbers of joints showed a decreasing trend, while the energy intensities of transmitted wave increased at first and then decreased.

The energy transmitting coefficients of blasting stress wave in single-joint, double-joints, triple-joints rock mass and the intact rock under different equal static loads are plotted in Figure 13.

It can be seen from Figure 13 that the energy transmitting coefficients of stress wave in the intact rock under the same static load were larger than that in the jointed rock mass, and coefficients decreased with the increase of the joint number. With the rise of static loads, the stress wave energy transmitting coefficients of the intact rock and jointed rock mass both increased first and then decreased. It was also found that with the growth of static loads, the difference of stress wave energy transmitting coefficients of the intact rock and jointed rock mass reduced gradually.

The energy dissipations in the blasting stress wave propagation in rock mass were mainly composed of the following two parts: the first one was the energy dissipation produced by the friction between the micro-cracks and the stress wave front diffusion in the intact rock; the other part was the energy dissipation when the stress wave was propagating at joints. In order to quantitatively study the energy dissipation of stress waves at joints, it was assumed that the two parts of energy dissipations in the jointed rock masses were independent. In Figure 13, the ratio of the stress wave energy transmitting coefficient between the jointed rock mass and the intact rock under the same biaxial equal static load was the energy transmitting coefficient of the stress wave passing through the joints, as shown in Figure 14.

Figure 14 shows that the more the number of joints, the smaller the energy transmitting coefficients of the stress wave, and coefficients increased with the static loads. The reason for this phenomenon was that the greater the static load, the greater the normal and tangential stresses on the joints, and the joints usually satisfy the nonlinear stress deformation relationship [4, 9]. Therefore, the normal and tangential stiffness of joints increased with the static loads, so the dissipation of the stress wave energy was reduced accordingly.

In summary, combined with Figures 10 and 14, the variation of stress wave energy transmitting coefficient with the increase of static loads in the jointed rock mass in

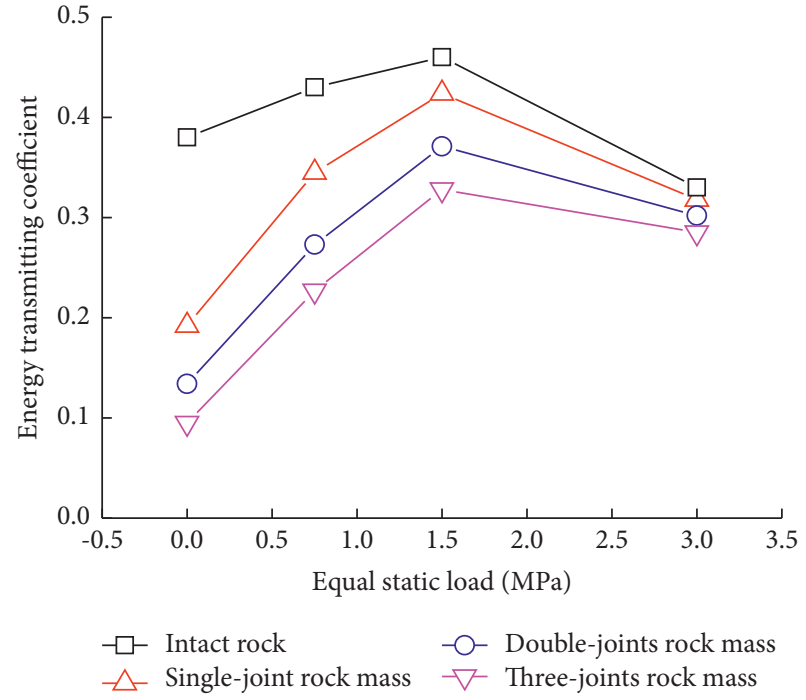

FIGURE 13: Energy transmitting coefficients of stress wave in intact rock and rock mass under different equal static loads.

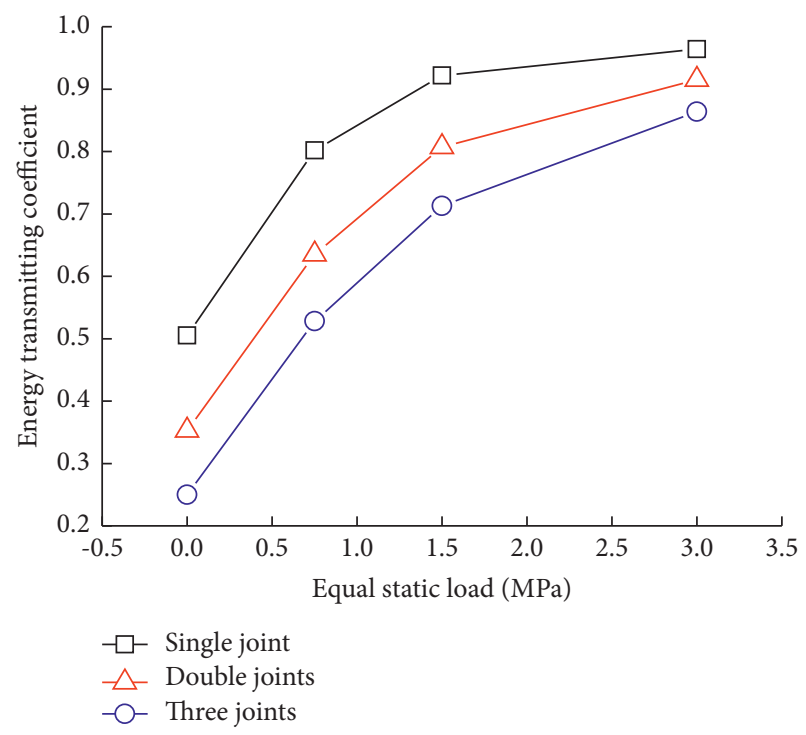

FIGURE 14: Energy transmitting coefficients of stress wave at joints under different equal static loads.

Figure 13 can be interpreted as follows: when the static load increased from 0 to $1.5 \mathrm{MPa}$, the energy transmission of stress wave in the intact rock and joints both grew, so the energy transmitting coefficient of the stress wave in jointed 
rock mass increased accordingly. With the increase of the static load, the energy transmission of stress wave at joints continued to improve, while the energy transmission in the intact rock declined sharply, which eventually led to the decrease of the energy transmitting coefficient.

5.2. Effect of the Number of Joints. The variation of energy transmitting coefficients of the stress wave in rock mass containing various numbers of joints under different equal biaxial static loads is shown in Figure 15.

Energy dissipation occurred when the stress wave propagating through each joint and the energy transmitting coefficients of the stress wave decreased with the increase of the joint number under the same static loads. Figure 15 shows that when the static loads were $0,0.75,1.5$, and $3 \mathrm{MPa}$, and the number of joints increased from 0 to 3 , the decrements of stress wave energy transmitting coefficients were $75 \%, 47.2 \%, 28.7 \%$, and $13.6 \%$, respectively. The results showed that when the static load increased, the reduction of the energy transmitting coefficient decreased with the increment of the number of joints.

The reason for the above results was that as the static loads increased, the stiffness of the joints rose, and the blasting stress wave energy transmission in the jointed rock mass increased. At the same time, when the blasting wave passed through the jointed rock mass, multiple transmission reflections occurred between the joints, which will enlarge the energy transmitting coefficient to some extent, and the larger the static load, the stronger the multiple transmission reflections effect. Therefore, with the growth of static load, the energy transmitting coefficients of stress wave passing through intact rock and jointed rock gradually became close.

The results showed that the larger the in-situ stress, the lower the influence of the number of joints on the energy transmission of the blasting stress wave, while the evolution of the micro-cracks in the intact rock played a leading role in the attenuation of the stress wave energy.

\section{Energy Transmission of Blasting Stress Wave Obliquely Incident In-Situ Stressed Rock Mass}

6.1. Effect of the Equal Biaxial Static Load. In the T2 and the T3 test samples, the energy intensities of the incident and transmitted wave passing through rock masses with different angles and quantities of joints under various equal biaxial static loads are shown in Tables 4 and 5, and the abbreviations ISW and TSW represent incident and transmitted stress wave, respectively.

Tables 4 and 5 indicated that with the increase of static loads, the transmitted wave energy intensities of the jointed rock mass with the same angle and number showed a trend of increasing first and then decreasing. Under the equivalent static load, the transmitted wave energy intensities had no obvious change with the raise of the joint angle. Based on the data in Tables 4 and 5, the energy transmitting coefficients of stress wave in single-joint and double-joints rock masses

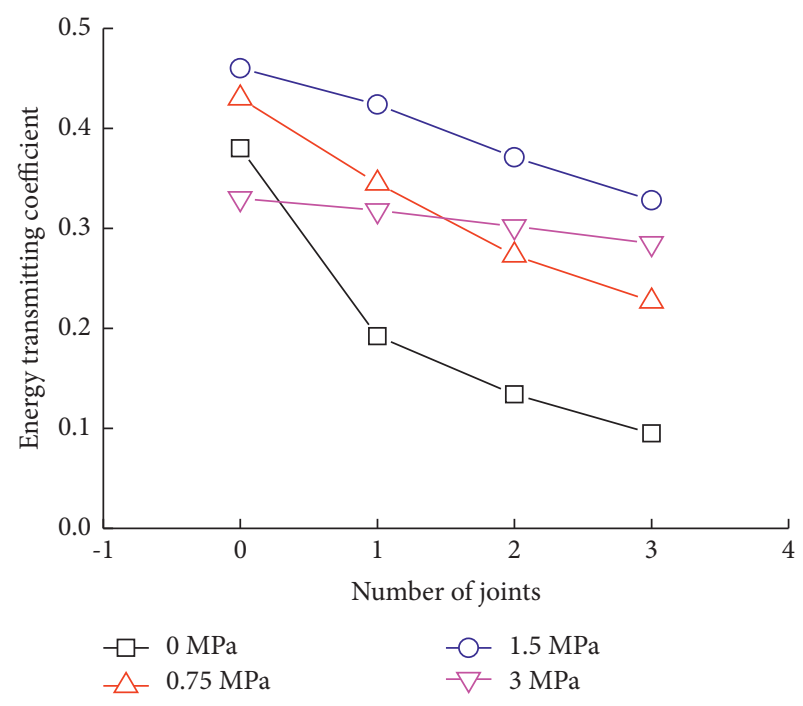

FIGURE 15: Influence of joint number on stress wave energy transmitting coefficients under different static loads.

with different angles under equal biaxial static loads are shown in Figure 16.

According to the joints layout diagram of the T2 and T3 test samples in Figure 4, the incident angles of stress wave in the $30^{\circ}, 60^{\circ}$, and $90^{\circ}$ single-joint and double-joint rock masses were $60^{\circ}, 30^{\circ}$, and $0^{\circ}$, respectively. Figure 16 shows that the energy transmitting coefficients increased at first and then decreased with the growth of static loads, while the coefficients dropped with the increase of the joint number under the same static load. Compared with Figure 13, it can be seen that as the static load rose from 0 , the jointed rock mass with different angles and numbers all showed a trend of first increasing and then decreasing, and the reason for this phenomenon is explained in Section 5.1.

6.2. Effect of the Lateral Static Load Coefficient. To compare with the test results of the intact rock, the variation of energy transmitting coefficients of the blasting stress wave in rock mass with different angles and quantities of joints was obtained, under unequal biaxial static loads, with the vertical static loading of $1.5 \mathrm{MPa}$ and lateral static load coefficients of $0.5,1$, and 2 respectively, as shown in Figure 17.

It can be seen from Figure 17 that with the rise of the lateral static load coefficient, the stress wave energy transmitting coefficients of the intact rock and jointed rock mass both first increased and then decreased. That was because the normal and tangential stresses on joints increased with the lateral static load coefficients, so the normal and tangential stiffness of joints grew simultaneously due to the nonlinear deformation characteristics of the joint. Therefore, with the increase of the lateral static load coefficient, the energy transmission of the stress wave at the joints was more efficient.

However, according to the analysis of Section 4.2, due to the change of differential stress, the energy transmission of stress wave in the intact rock mass increased first and then decreased with the growth of the lateral pressure 
TABLe 4: Energy intensities of incident and transmitted stress wave in single-joint rock mass under different equal biaxial static loads.

\begin{tabular}{|c|c|c|c|c|c|c|}
\hline \multirow{3}{*}{ Static loads $(\mathrm{MPa})$} & \multicolumn{6}{|c|}{ Single-joint rock mass } \\
\hline & \multicolumn{2}{|c|}{$30^{\circ}$} & \multicolumn{2}{|c|}{$60^{\circ}$} & \multicolumn{2}{|c|}{$90^{\circ}$} \\
\hline & ISW $\left(\mathrm{J} / \mathrm{m}^{2}\right)$ & $\operatorname{TSW}\left(\mathrm{J} / \mathrm{m}^{2}\right)$ & ISW $\left(J / \mathrm{m}^{2}\right)$ & TSW $\left(\mathrm{J} / \mathrm{m}^{2}\right)$ & ISW $\left(\mathrm{J} / \mathrm{m}^{2}\right)$ & $\operatorname{TSW}\left(\mathrm{J} / \mathrm{m}^{2}\right)$ \\
\hline 0 & 20.12 & 4.73 & 23.45 & 5.14 & 22.43 & 4.60 \\
\hline 0.75 & 17.92 & 5.41 & 15.27 & 4.86 & 16.87 & 5.67 \\
\hline 1.5 & 13.68 & 5.32 & 12.53 & 5.08 & 12.76 & 5.59 \\
\hline 3 & 7.54 & 2.02 & 5.93 & 1.69 & 6.67 & 2.06 \\
\hline
\end{tabular}

TABLE 5: Energy intensities of incident and transmitted stress wave in double-joints rock mass under different equal biaxial static loads.

\begin{tabular}{|c|c|c|c|c|c|c|}
\hline \multirow{3}{*}{ Static loads (MPa) } & \multicolumn{6}{|c|}{ Double-joints rock mass } \\
\hline & \multicolumn{2}{|c|}{$30^{\circ}$} & \multicolumn{2}{|c|}{$60^{\circ}$} & \multicolumn{2}{|c|}{$90^{\circ}$} \\
\hline & ISW $\left(J / \mathrm{m}^{2}\right)$ & TSW $\left(\mathrm{J} / \mathrm{m}^{2}\right)$ & ISW $\left(J / \mathrm{m}^{2}\right)$ & TSW $\left(\mathrm{J} / \mathrm{m}^{2}\right)$ & ISW $\left(\mathrm{J} / \mathrm{m}^{2}\right)$ & TSW $\left(\mathrm{J} / \mathrm{m}^{2}\right)$ \\
\hline 0 & 22.87 & 3.45 & 21.36 & 2.82 & 23.54 & 2.92 \\
\hline 0.75 & 17.54 & 4.46 & 18.43 & 4.90 & 16.42 & 4.71 \\
\hline 1.5 & 14.65 & 5.02 & 15.28 & 5.47 & 14.73 & 5.77 \\
\hline 3 & 7.21 & 1.87 & 5.62 & 1.53 & 6.33 & 1.84 \\
\hline
\end{tabular}

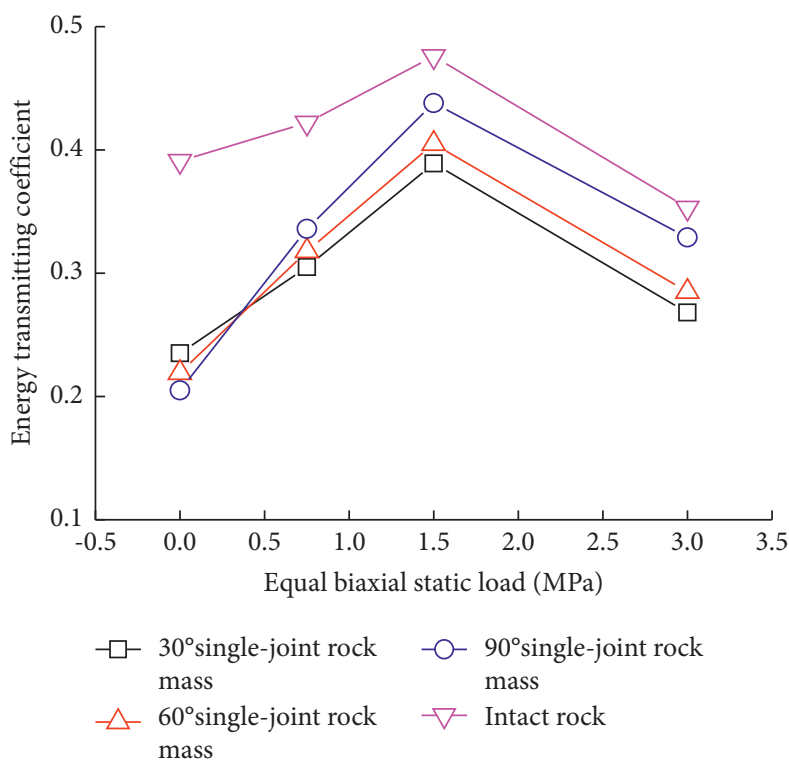

(a)

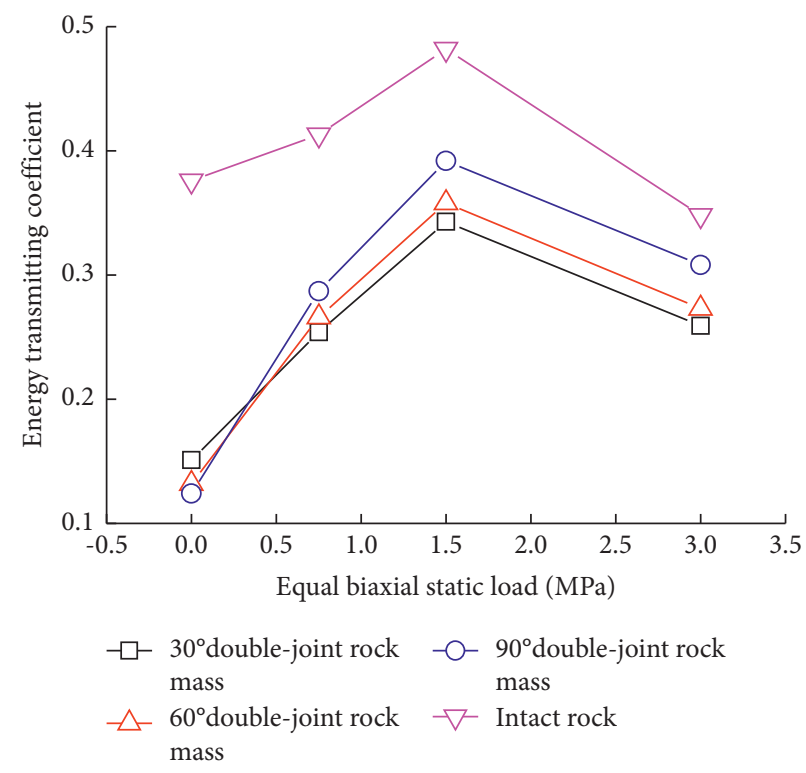

(b)

FIGURE 16: Energy transmitting coefficients of stress wave in jointed rock masses with different angles and numbers under equal biaxial static loads. (a) Single-joint rock mass. (b) Double-joints rock mass.

coefficient, as shown in Figure 17. It also can be found that the variations of stress wave energy transmitting coefficient of the intact rock and jointed rock mass were identical with the increment of the lateral coefficient, indicating that when the differential stress increased, the stress wave energy dissipation in the intact rock was dominant in the process of stress wave passing through jointed rock mass.

6.3. Effect of the Joint Angle. In the blasting excavation of underground engineering, the spatial distribution of joints in the surrounding rock mass was commonly random, so it is necessary to study the effect of the joint angle on stress wave energy transmission. Based on the data in Tables 4 and 5 , the influence of the joint angle on the energy transmission of the stress wave under equal biaxial static loads is shown in Figure 18.

Figure 18 shows that when the static load was zero, the stress wave energy transmitting coefficients decreased with the increase of joint angle (i.e., the decrease of the stress wave incident angle), while when the static load was greater than zero, the coefficients increased with the joint angle. The reason may be that the normal and tangential stiffness of the joint varied with the joint angle under the equal biaxial static loads and blasting stress wave. 


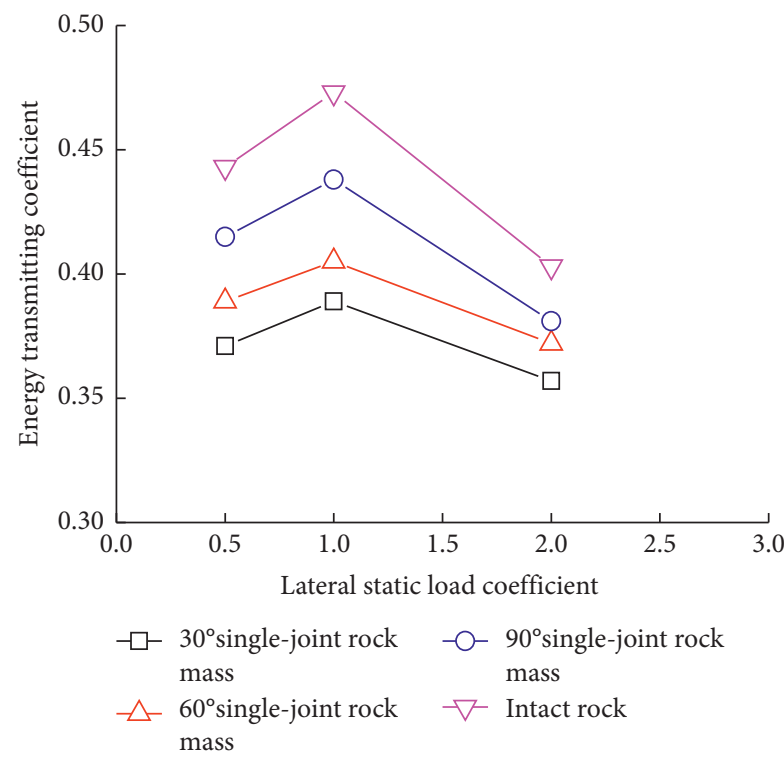

(a)

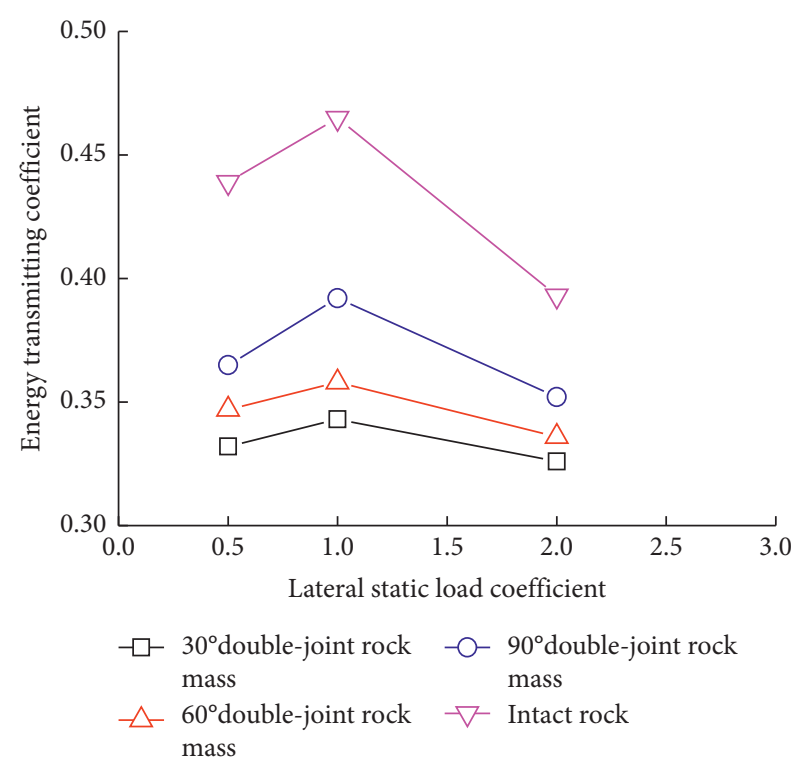

(b)

FIGURE 17: Energy transmitting coefficients of blasting stress wave in jointed rock masses under different lateral static load coefficients. (a) Single-joint rock mass. (b) Double-joints rock mass.

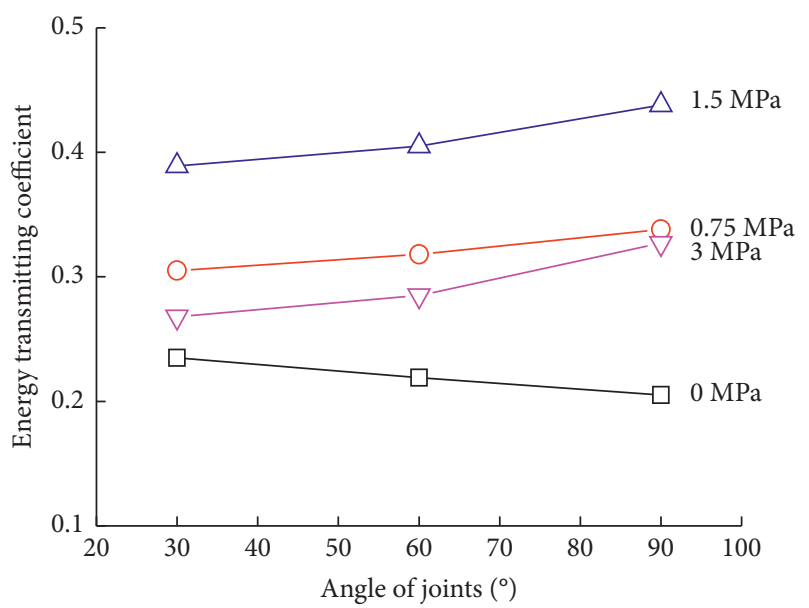

(a)

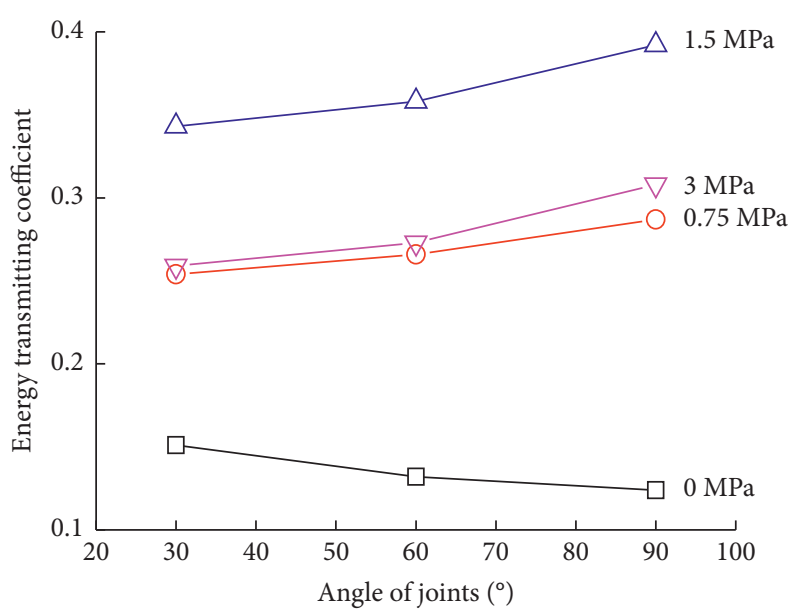

(b)

FIGURE 18: Influence of joint angle on energy transmitting coefficient of stress wave under equal biaxial static loads. (a) Single-joint rock mass.. (b) Double-joints rock mass.

For the unequal biaxial static loading, the loading condition with vertical static load of $1.5 \mathrm{MPa}$ was selected, and the effects of the joint angle on the energy transmission of the stress wave in jointed rock mass are shown in Figure 19.

It can be seen from Figure 19 that the energy transmitting coefficients of the stress wave increased with the joint angle under the same lateral static load coefficient. When the lateral static load coefficient and the angle of joint were constant, the energy transmitting coefficient decreased with the increase of the number of joints.
The above results showed that the energy transmitting coefficients of stress wave in the jointed rock mass increased with the increase of the angle of joint (i.e., the decrease of the angle of incident stress wave), and while the static loads were greater than 0 , the energy transmitting coefficient was the largest when the stress wave normal incident the joints. For the practical underground engineering, the state of in-situ stress was highly complex, and the spatial distribution of joints in the rock mass was also complicated. Due to the high cost of dynamic test, the joint angles set in the test were only $30^{\circ}, 60^{\circ}$, and $90^{\circ}$, which may lead to the effects of joint angle 


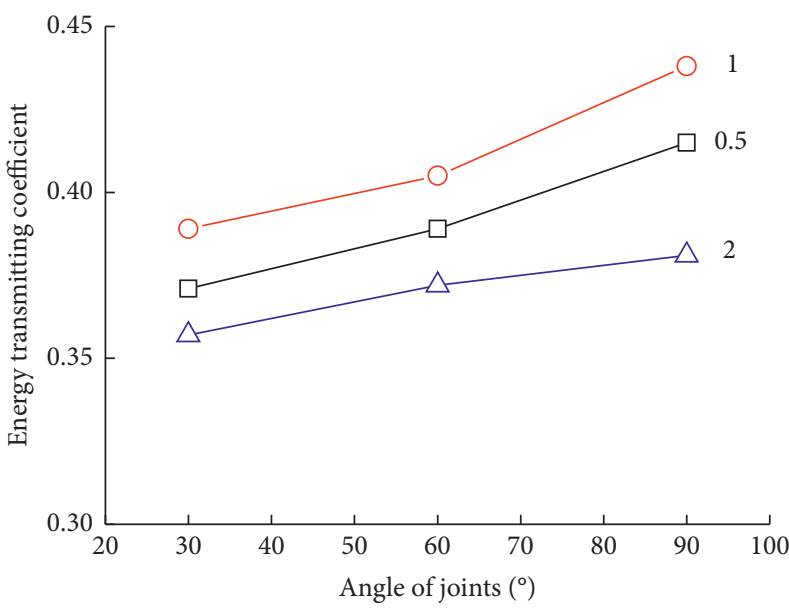

(a)

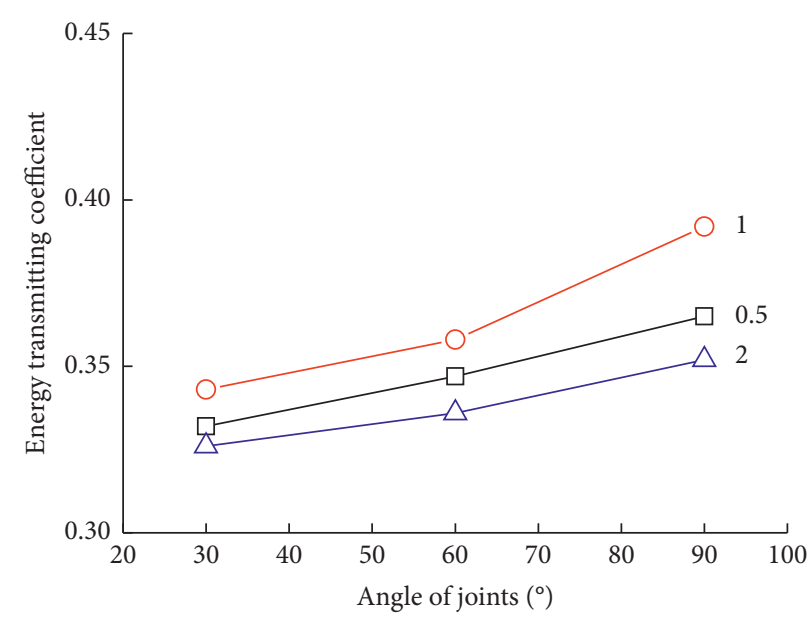

(b)

FIGURE 19: Influence of joint angle on energy transmitting coefficient of stress wave under unequal biaxial static loads. (a) Single-joint rock mass. (b) Double-joints rock mass.

on the energy transmission of blasting stress wave under different in-situ stress states and cannot reflect the actual situation. Furthermore, theoretical and numerical simulation research should be carried out for more quantitative analysis.

\section{Conclusion}

(1) The energy transmission of the blasting stress wave in the intact rock was closely related to the evolution of internal micro-cracks. Under equal biaxial static loading, when the static load was less than $25.6 \%$ of the uniaxial compressive strength $R_{\mathrm{c}}$, the microcracks in the intact rock were closed, resulting in the increase of the stress wave energy transmitting coefficients with the static load. Meanwhile, there was a critical static load $R_{\mathrm{cr}}\left(25.6 \% R_{\mathrm{c}}<R_{\mathrm{cr}}<51.2 \% R_{\mathrm{c}}\right)$, when the static load was greater than $R_{\mathrm{cr}}$, the number of micro-cracks in the the intact rock had grown, resulting in the decrease of stress wave energy transmitting coefficients. Under unequal biaxial static loading, with the rise of differential stress, the number of micro-cracks in the intact rock continued to grow, resulting in the decline of stress wave energy transmitting coefficients, and the coefficients increased first and then decreased with the lateral pressure coefficient.

(2) The energy transmission of the blasting stress wave in jointed rock mass was affected by both the intact rock and joints. Due to the nonlinear deformation characteristics of joints, the energy transmission of the stress wave increased with the in-situ stress, but the increment declined gradually. The energy transmitting coefficients of the jointed rock mass firstly increased and then decreased with the rise of static load and lateral static load coefficient. It is indicated that when the in-situ stress was low, the presence of in-situ stress can enhance the energy transmission of the stress wave in the rock mass to some extent, so as to optimize the explosive energy distribution in the rock mass during blasting excavation, which was beneficial to the full fragment of rock mass. When the in-situ stress was relatively large, the stress wave energy dissipation in the intact rock was dominant in the process of stress wave passing through jointed rock mass, whereas the effect of joints on energy transmission of the stress wave was reduced, and the charge of blasting excavation should be increased to achieve the blasting effect.

(3) When the stress wave incident the rock mass containing different angles and numbers of joints, the energy transmitting coefficients of the stress wave dropped with the growth of the number of joints, and the larger the in-situ stress, the lower the influence of the number of joints on the energy transmission of the blasting stress wave. The stress wave energy transmitting coefficients in the jointed rock mass increased with the angle of joint (i.e., the decrease of the angle of incident stress wave) under static loading; when the stress wave vertically incident the joints, the energy transmitting coefficient was the largest. Therefore, in the blasting excavation of the underground rock mass, the connection line of blast holes should be perpendicular to the dominant joints in the rock mass, to ensure the efficient transmission of blasting energy.

(4) In the blasting excavation of the underground rock mass, the in-situ stress and the spatial distribution of joints were complicated and significantly affect the energy transmission of the blasting stress wave, especially for long tunnels and caverns. Therefore, in underground engineering, the orientation of the dominant structural plane and the in-situ stress state of the surrounding rock mass should be determined first, and the blasting parameters can be optimized 
accordingly, so as to improve the utilization of explosive energy and achieve the designed blasting effect.

In this paper, due to the limitation of test conditions and the complexity of influence factors, the in-situ stress state and the distribution of joints in the rock mass were relatively simple. However, for practical engineering, the situation is more complicated, which is also the focus of further research.

\section{Data Availability}

The data used to support the findings of this study are available from the corresponding author upon request.

\section{Conflicts of Interest}

The authors declare that they have no conflicts of interest.

\section{Acknowledgments}

This study was supported by the Natural Science Foundation of Hubei Province, China (2020CFB428), Innovation Group Project of the Natural Science Foundation of Hubei Province, China (2020CFA043), Key Research and Development Project of Hubei Province, China (2020BCA084), the National Natural Science Foundation of China (51774222), Open Research Fund of Hubei Key Laboratory of Blasting Engineering (HKLBEF202006), and the Research Start-Up Foundation of Jianghan University (1027-06020001).

\section{References}

[1] Ö. Aydan, ISRM Book Series 3: Rock Dynamics, CRC Press, Boca Raton, FL, USA, 2017.

[2] L. J. Pyrak-Nolte, L. R. Myer, and N. G. W. Cook, "Transmission of seismic waves across single natural fractures," Journal of Geophysical Research Solid Earth, vol. 95, no. B6, pp. 8617-8638, 1990.

[3] L. J. Pyrak-Nolte, L. R. Myer, and N. G. W. Cook, "Anisotropy in seismic velocities and amplitudes from multiple parallel fractures," Journal of Geophysical Research Atmospheres, vol. 95, no. B7, pp. 11345-11358, 1990.

[4] J. Zhao and J. G. Cai, "Transmission of elastic P-waves across single fractures with a nonlinear normal deformational behavior," Rock Mechanics and Rock Engineering, vol. 34, no. 1, pp. 3-22, 2001.

[5] A. Perino, J. B. Zhu, J. C. Li, G. Brala, and J. Zhao, "Theoretical methods for wave propagation across jointed rock masses," Rock Mechanics and Rock Engineering, vol. 43, no. 6, pp. 799-809, 2010.

[6] M. Schoenberg, "Elastic wave behavior across linear slip interfaces," Journal of the Acoustical Society of America, vol. 68, no. 5, pp. 1516-1521, 1980.

[7] J. Zhao, X. B. Zhao, and J. G. Cai, "A further study of P-wave attenuation across parallel fractures with linear deformational behavior," International Journal of Rock Mechanics and Mining Sciences, vol. 43, pp. 776-788, 2006.

[8] X. B. Zhao, J. Zhao, and J. G. Cai, "P-wave transmission across fractures with nonlinear deformational behaviour," International Journal for Numerical and Analytical Methods in Geomechanics, vol. 30, no. 11, pp. 1097-1112, 2006.
[9] J. C. Li and G. W. Ma, "Analysis of blast wave interaction with a rock joint," Rock Mechanics and Rock Engineering, vol. 43, no. 6, pp. 777-787, 2010.

[10] B. L. Gu, R. Suárez-Rivera, K. T. Nihei, and L. R. Myer, "Incidence of plane waves upon a fracture," Journal of Geophysical Research: Solid Earth, vol. 101, pp. 25337-25346, 1996.

[11] J. G. Caj and J. Zhao, "Effects of multiple parallel fractures on apparent attenuation of stress waves in rock masses," International Journal of Rock Mechanics and Mining Sciences, vol. 37, no. 4, pp. 661-682, 2000.

[12] J. C. Li, H. B. Li, G. W. Ma, and J. Zhao, "A time-domain recursive method to analyse transient wave propagation across rock joints," Geophysical Journal International, vol. 188, no. 2, pp. 631-644, 2012.

[13] J. Zhao, J. G. Cai, X. B. Zhao, and H. B. Li, "Dynamic model of fracture normal behaviour and application to prediction of stress wave attenuation across fractures," Rock Mechanics and Rock Engineering, vol. 41, no. 5, pp. 671-693, 2008.

[14] A. Perino, R. Orta, and G. Barla, "Wave propagation in discontinuous media by the scattering matrix method," Rock Mechanics and Rock Engineering, vol. 45, no. 6, pp. 901-918, 2012.

[15] J. C. Li, W. Wu, H. B. Li, J. B. Zhu, and J. Zhao, "A thin-layer interface model for wave propagation through filled rock joints," Journal of Applied Geophysics, vol. 91, pp. 31-38, 2013.

[16] J. C. Li, H. B. Li, Y. Y. Jiao, Y. Q. Liu, X. Xia, and C. Yu, "Analysis for oblique wave propagation across filled joints based on thin-layer interface model," Journal of Applied Geophysics, vol. 102, pp. 39-46, 2014.

[17] J. B. Zhu, X. B. Zhao, J. C. Li, G. F. Zhao, and J. Zhao, "Normally incident wave propagation across a joint set with the virtual wave source method," Journal of Applied Geophysics, vol. 73, pp. 283-288, 2011.

[18] J. B. Zhu and J. Zhao, "Obliquely incident wave propagation across rock joints with virtual wave source method," Journal of Applied Geophysics, vol. 88, pp. 23-30, 2013.

[19] H. Kolsky, "Stress waves in solids," Journal of Sound and Vibration, vol. 1, no. 1, pp. 88-110, 1964.

[20] Y. Ju, L. Sudak and H. P. Xie, "Study on stress wave propagation in fractured rocks with fractal joint surfaces," International Journal of Solids and Structures, vol. 44, no. 13, pp. 4256-4271, 2007.

[21] J. J. Feng, E. Y. Wang, L. Chen, X. L. Li, Z. Y. Xu, and G. A. Li, "Experimental study of the stress effect on attenuation of normally incident P-wave through coal," Journal of Applied Geophysics, vol. 132, pp. 25-32, 2016.

[22] X. B. Li, Z. L. Zhou, T. S. Lok, L. Hong, and T. Yin, "Innovative testing technique of rock subjected to coupled static and dynamic loads," International Journal of Rock Mechanics and Mining Sciences, vol. 45, no. 5, pp. 739-748, 2008.

[23] J. F. Jin, X. B. Li, T. B. Yin, and X. J. Zhou, "Effect of axial static stress of elastic bar on incident stress wave under axial impact loading," Engineering mechanics, vol. 30, no. 11, pp. 21-27, 2013, in Chinese.

[24] M. D. Sharma and N. J. Garg, "Wave velocities in a prestressed anisotropic elastic medium," Journal of Earth System Science, vol. 115, no. 2, pp. 257-265, 2006.

[25] A. N. Guz, V. M. Nazarenko, and V. L. Bogdanov, "Combined analysis of fracture under stresses acting along cracks," Archive of Applied Mechanics, vol. 83, no. 9, pp. 1273-1293, 2013.

[26] L. F. Fan and H. Y. Sun, "Seismic wave propagation through an in-situ stressed rock mass," Journal of Applied Geophysics, vol. 121, pp. 13-20, 2015. 
[27] Y. Cheng, Z. P. Song, J. F. Jin, J. B. Wang, and T. Wang, "Experimental study on stress wave attenuation and energy dissipation of sandstone under full deformation codition," Arabian Journal of Geosciences, vol. 12, pp. 736-749, 2019.

[28] T. T. Liu, J. C. Li, H. B. Li, and S. B. Chai, "Energy analysis of stress wave propagation across parallel nonlinear joints," Chinese Journal of Rock Mechanics and Engineering, vol. 32, no. 8, pp. 1610-1617, 2013, in Chinese.

[29] W. H. Wang, H. Hao, X. B. Li, Z. Yan, and F. Q. Gang, "Effects of a single open joint on energy transmission coefficients of stress waves with different waveforms," Rock Mechanics and Rock Engineering, vol. 48, no. 5, pp. 2157-2166, 2015.

[30] J. C. Li, L. F. Rong, H. B. Li, and S. N. Hong, "An SHPB test study on stress wave energy attenuation in jointed rock masses," Rock Mechanics and Rock Engineering, vol. 52, no. 2, pp. 403-420, 2018.

[31] Q. Dong, "Model test study on propagation law of plane stress wave in jointed rock mass under different in-situ stresses," IOP Conference Series: Earth and Environmental Science, vol. 100, Article ID 012009, 2017.

[32] Q. Dong, X. P. Li, and J. H. Huang, "Model test study on cylindrical blasting stress wave propagation across jointed rock mass with different initial stresses," Advances in Civil Engineering, vol. 2020, Article ID 8881302, 13 pages, 2020.

[33] M. Cai, P. K. Kaiser, and Y. Tasaka, "Generalized crack initiation and crack damage stress thresholds of brittle rock masses near underground excavations," International Journal of Rock Mechanics and Mining Sciences, vol. 41, no. 5, pp. 833-847, 2004. 